\title{
Human Resources in Europe. Estimation, Clusterization, Machine Learning and Prediction
}

ANGELO LEOGRANDE ( $\square$ angelo.economics@gmail.com )

LUM UNIVERSITY

\section{ALBERTO COSTANTIELLO}

LUM UNIVERSITY

\section{Research Article}

Keywords: Innovation and Invention: Processes and Incentives, Management of Technological Innovation and R\&D, Technological Change: Choices and Consequences, Diffusion Processes Intellectual Property and Intellectual Capital, Open Innovation, Government Policy.

Posted Date: September 16th, 2021

DOl: https://doi.org/10.21203/rs.3.rs-910383/v1

License: (c) (i) This work is licensed under a Creative Commons Attribution 4.0 International License. Read Full License 


\title{
Human Resources in Europe. Estimation, Clusterization, Machine Learning and Prediction
}

\author{
Angelo Leogrande ${ }^{1}$, Alberto Costantiello ${ }^{2}$
}

\begin{abstract}
We estimate the relationships between innovation and human resources in Europe using the European Innovation Scoreboard of the European Commission for 36 countries for the period 2010-2019. We perform Panel Data with Fixed Effects, Random Effects, Pooled OLS, Dynamic Panel and WLS. We found that Human resources is positively associated to "Basic-school entrepreneurial education and training", "Employment MHT manufacturing KIS services", "Employment share Manufacturing $(S D) "$, "Lifelong learning", "New doctorate graduates", "R\&D expenditure business sector", " $R \& D$ expenditure public sector", "Tertiary education". Our results also show that "Human Resources" is negatively associated to "Government procurement of advanced technology products", "Medium and high-tech product exports", "SMEs innovating in-house", "Venture capital". In adjunct we perform a clusterization with k-Means algorithm and we find the presence of three clusters. Clusterization shows the presence of Central and Northern European countries that has higher levels of Human Resources, while Southern and Eastern Europe has very low degree of Human Resources. Finally, we use seven machine learning algorithms to predict the value of Human Resources in Europe Countries using data in the period 2014-2021 and we show that the linear regression algorithm performs at the highest level.
\end{abstract}

JEL CODE: O31, O32, O34, O36, O38.

Keywords: Innovation and Invention: Processes and Incentives, Management of Technological Innovation and $R \& D$, Technological Change: Choices and Consequences, Diffusion Processes Intellectual Property and Intellectual Capital, Open Innovation, Government Policy.

\section{Introduction}

In this article we analyze the determinants of human resources that related to innovation. We use data from the European Innovation Scoreboard of the European Commission for the period 2010-2019 for 36 countries $^{3}$. The level of human resources is positively associated to the level of economic growth even in the classical and endogenous theories [1], [2]. Also, in the theory of Schumpeter there is a positive role for the human resources in the sense of the ability of entrepreneurs to operate as Demiurge of the economic development [3]. The level of human resources is relevant to human capital and promote innovation [4]. The degree of human resources in its ability to improve innovation has a positive effect on sales [5], firms' investments in new products and services [6]. The presence of innovators among European countries is associated to the ability to produce intangible assets that depends on human resources [7]. European countries that sustain high level of human resources also to invest more in innovation and Research and Development-R\&D [8]. Innovation has a positive effect on employment and specifically, in European countries that have a higher level of

\footnotetext{
${ }^{1}$ Assistant Professor at LUM University- Giuseppe Degennaro, S.S. 100 Km. 18, 70010, Casamassima, Ba, Italy.

${ }^{2}$ LUM University- Giuseppe Degennaro, S.S. 100 Km. 18, 70010, Casamassima, Ba, Italy.

${ }^{3}$ Countries are Austria, Belgium, Bulgaria, Croatia, Cyprus, Czechia, Denmark, Estonia, Finlandia, France, Germany, Greece, Hungary, Iceland, Ireland, Israel, Italy, Latvia, Lithuania, Luxembourg, Malta, Montenegro, Netherlands, Norway, Poland, Portugal, Romania, Serbia, Slovakia, Slovenia, Spain, Switzerland, Turkey, Ukraine.
} 
human resources also the impact of innovation on employment is higher [9]. European countries that have a more developed economic systems, based on more skilled and educated human resources, also have a greater level of the attractiveness of research systems [10]. At a corporate level the increase in employment in European big firms is positively associated to an increase in investment in Research and Development with a relevant impact on net sales [11]. There is also a positive relationship between human resources and the creation of an innovation friendly environment in European countries [12]. Universities have a strategic role in promoting the development of human resources, and social capital [13]. Human resources capabilities improve the competitiveness of tech firms [14]. To strengthen the relationship between human resources and innovation it is necessary to apply a quali-quantitative political economy oriented to promote a growth in R\&D [15] and high skills professionals. Human resources matter not only for innovation technology but also for social innovation [16]. Creative industries that practice soft innovation through co-creation require high skilled human resources [17]. Human resources have a role in creating the condition by which corporations can adopt innovation technology at an enterprise level [18]. Firms that are interested in implementing innovation require to produce more flexible organizational structure through more qualified human resources [19]. Digital transformation can be realized only with the implementation of digital skills among human resources through investments in education and organizational innovation [20]. Human resources are also relevant to apply strategies of innovation management through the hiring of high skilled workers and experienced managers [21]. There is a positive relationship between human resources, technological innovation, and change management also in the handicraft sector [22]. The improvement of human resources in universities can increase the level of organizational commitment of staff [23]. The human resources management in innovative firms is relevant since the market for technology is characterized by organizational change with new professionals and new skills that enter in the context of the enterprise and require to be recognized in the firm's structure [24]. The ability of a firm to manage efficiently human resources driving them towards innovative activities, during a financial crisis, depends on the financial stability of banking partners i.e.: if a firm has a banking partner that suffer less during a financial crisis, then the firm show a deeper capability to orient the human resources in the sense of innovation [25]. Human resources are a driver to promote innovation, Gdp growth and competitiveness at a national level in Europe [26]. Human Resource Management-HRM and Research and Development-R\&D have a positive role in promoting the ability of firm to innovate and both strongly depend on top management support [27].

The article continues as follows: the second paragraph presents the econometric model, the third paragraph contains the clusterization analysis with the k-Means algorithm optimized with the Silhouette coefficient, the third paragraph proposes a confrontation among seven different algorithms of machine learning and predictions, the fourth paragraph concludes.

\section{The Econometric Model}

We have estimated the following econometric model: 


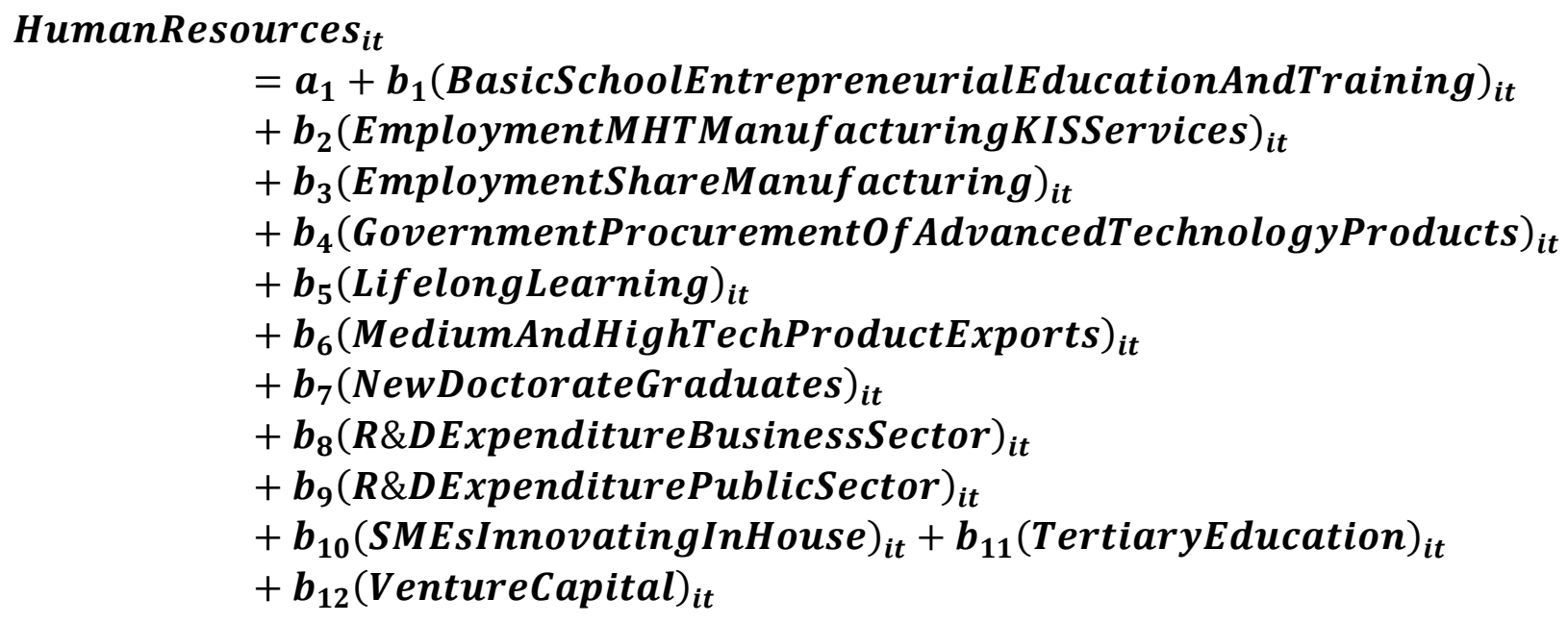

Where $i$ is equal to 36 and $t$ is the period 2010-2019.

We have used Dynamic Panel, Pooled OLS, Fixed Effects, Random Effects, WLS. We found that the level of Human Resources is positively associated to:

- Basic-school entrepreneurial education and training: is defined in the European Innovation scoreboard as an indicator that «[...] measures the extent to which training in creating or managing SMEs is incorporated within the education and training system at primary and secondary school levels». This means that if the managerial and entrepreneurial culture is promoted in schools there is a global positive impact on the ability of that country to have an improvement in human capital with positive effect in the sense of human resources.

- Employment MHT manufacturing KIS services: this variable is defined as the number «[...] of employed persons in knowledge-intensive activities in business industries». This means that if there are firms that operates in knowledge-intensive activities, they can have a positive impact on human capital either offering new products and services to customers either creating a demand for high level products and services for their suppliers. The combined effects on consumers and suppliers generate an improvement in the level of human resources at a country level.

- Employment Share in Manufacturing: is the percentage of employment in manufacturing industries. The presence of manufacturing industries with a relevant employment share as a percentage of total employment per countries has a positive impact of human resources. Manufacturing industries requires specialized employee and high skilled human resources especially in the case of medium and high-tech firms.

- Lifelong learning: is a measure of the percentage of the population in the age 25-64 that participate in education and training. The learning activity considered in this variable is either formal either informal and is oriented to improve the level of knowledge, skills and know how in the population. Learning activities cannot be confused with cultural and sporting activities. The analysis shows that the increasing percentage of population that practice lifelong learning has a positive impact in improving the level of human resources.

- New doctorate graduates: is the number of doctorate graduates per thousand for the population in the age 25-34. The increasing number of doctorate graduates is positively associated to an improvement in human resources. But this indicator has a limitation since it is possible that there are doctorate graduates also in the population 34-65 due to the new Ph.D. programs that are designed for the working professionals and employees. 
- $R \& D$ expenditure business sector: is a variable that consider all the expenditures in the business sector as a percentage of Gross Domestic Product-GDP. The variable can indicate the relevance of the process of knowledge creation in the private sector even if the large part of innovation and knowledge is generated in connection within the pharmaceutical and the chemical industries. This variable is positively associated to the improvement of human resources at a country level. The greater the expenditure of the business sector in Research and Development the greater the impact on human resources.

- $R \& D$ expenditure public sector: the variable considers all the expenditure in Research and Development either at a government level either in the educational sector. The degree of R\&D expenditure can promote the economic growth in the long run, with a positive impact on the ability of firms and productive organizations to generate more innovative and knowledge intense products and services. Specifically, the increase in the level of R\&D expenditure in the public sector is positively associated to an improve in the level of human resources.

- Tertiary education: percentage of the population in the age 25-34 that has completed a tertiary education. This indicator has two limitations: on the one side it does not consider the possibility of the people in the population 35-65 that can be enrolled in tertiary education program, and on the other side it comprehends either scientific and non-scientific skills acquired in the educational system at a national level. There is a positive relationship between the increasing in tertiary education and the improvement of human resources in European Countries.

\begin{tabular}{|l|l|l|l|}
\hline \multicolumn{1}{|c|}{ Variables } & Label & Relations \\
\hline $\boldsymbol{y}$ & Human Resources & A23 & \\
\hline $\boldsymbol{x}_{\mathbf{1}}$ & Basic-school entrepreneurial education and training & $A 4$ & + \\
\hline $\boldsymbol{x}_{\mathbf{2}}$ & Employment MHT manufacturing KIS services & $A 11$ & + \\
\hline $\boldsymbol{x}_{\mathbf{3}}$ & Employment share Manufacturing & $A 12$ & + \\
\hline $\boldsymbol{x}_{\mathbf{4}}$ & Government procurement of advanced technology products & $A 22$ & - \\
\hline $\boldsymbol{x}_{\mathbf{5}}$ & Lifelong learning & $A 32$ & + \\
\hline $\boldsymbol{x}_{\mathbf{6}}$ & Medium and high-tech product exports & $A 35$ & - \\
\hline $\boldsymbol{x}_{\mathbf{7}}$ & New doctorate graduates & $A 37$ & + \\
\hline $\boldsymbol{x}_{\mathbf{8}}$ & R\&D expenditure business sector & $A 46$ & + \\
\hline $\boldsymbol{x}_{\mathbf{9}}$ & R\&D expenditure public sector & $A 47$ & + \\
\hline $\boldsymbol{x}_{\mathbf{1 0}}$ & SMEs innovating in-house & $A 52$ & - \\
\hline $\boldsymbol{x}_{\mathbf{1 1}}$ & Tertiary education & $A 53$ & + \\
\hline $\boldsymbol{x}_{\mathbf{1}}$ & Venture capital & $A 59$ & - \\
\hline
\end{tabular}

Figure 1. Variables, Labels, and main relationships of the panel data econometric model estimated.

The level of Human Resources is negatively associated to:

- Government procurement of advanced technology products: consider the ability of a government to improve the level of technology at a country level through its procurement i.e. by the means of the public demand for medium and high tech products and services. Our analysis shows that there is a negative relationship between the public demand of high-tech products and services and its impact on human resources. 
- Medium and high-tech product exports: it's a measure of the level of exports for high and medium products. There is a negative impact of medium and high-tech product exports and the level of human resources at a country level. The fact that the exports of medium and hightech product is negatively associated with human resources can be explained considering that if a firm exports high tech products probably the internal demand for that product is low. And if the domestic demand for a high-tech product is low or insufficient then the level of human capital in that country can be low and insufficient, too.

- SMEs innovating in-house: is the percentage of Small and Medium-Sized Enterprises-SMEs that can introduce in-house innovation activities in respect to the total number of SMEs. SMEs activities of innovation is considered as "in-house" either in the case in which the firm creates innovation by itself either in co-operation with other enterprises and organisations. In-house innovation is considered either as product innovation either as process innovation. This variable is negatively associated to human resources. The reason for this negative relationship can be better understood considering that generally the level of human resources applied in SMEs is lower than the level of human resources applied in greater corporations.

- Venture capital: is a measure of the level of private equity that is invested in companies. The European Innovation Scoreboard considers as venture capital expenditure only three operations: the financing of startups, the expansion of capital and the replacement of capital. The variable venture capital expenditure is expressed as a share of the Gross Domestic Product. There is a negative relationship between venture capital expenditure and the level of Human resources in Europe.

\begin{tabular}{|c|c|c|c|c|c|c|c|c|c|c|c|c|c|c|c|}
\hline \multirow[b]{3}{*}{ const } & \multicolumn{3}{|c|}{ DYNAMIC PANEL } & \multicolumn{3}{|c|}{ POOLED OLS } & \multicolumn{3}{|c|}{ FIXED EFFECTS } & \multicolumn{3}{|c|}{ RANDOM EFFECTS } & \multicolumn{3}{|c|}{ WLS } \\
\hline & \multirow{2}{*}{\begin{tabular}{|r|} 
Coefficient \\
0,0362006 \\
\end{tabular}} & \multicolumn{2}{|c|}{ P-value } & \multirow{2}{*}{\begin{tabular}{|r|r|} 
Coefficient \\
1,66348 \\
\end{tabular}} & \multicolumn{2}{|c|}{ P-value } & \multirow{2}{*}{\begin{tabular}{|c|} 
Coefficient \\
0,174644 \\
\end{tabular}} & \multicolumn{2}{|c|}{ P-value } & \multirow{2}{*}{\begin{tabular}{c|} 
Coefficient \\
0,258045
\end{tabular}} & \multicolumn{2}{|c|}{ P-value } & \multirow{2}{*}{\begin{tabular}{|r|} 
Coefficient \\
0,164731 \\
\end{tabular}} & \multicolumn{2}{|c|}{ P-value } \\
\hline & & 0,9289 & & & 0,0302 & $* *$ & & 0,7588 & & & 0,8219 & & & 0,6702 & \\
\hline$A 4$ & 0,212464 & $<0,0001$ & $* * *$ & 0,151388 & $<0,0001$ & **** & 0,131767 & $<0,0001$ & *** & 0,136655 & $<0,0001$ & & 0,18446 & $<0,0001$ & \\
\hline$A 11$ & & 0,0002 & **** & & & $* * *$ & & & *** & $0,215 \mathbf{1} 03$ & & *** & 0,151996 & $<0,0001$ & \\
\hline$A 12$ & 0,140276 & & $* * *$ & & & *** & & & $* * *$ & 0,1595 & & $* * *$ & 0,157114 & & $* *$ \\
\hline$A 22$ & $-0,412619$ & $<0$, & $* * *$ & & & $* * *$ & $-0,464164$ & & $* * *$ & $-0,470201$ & & $* * *$ & $-0,40288$ & & $* *$ \\
\hline$A 32$ & 0,196726 & $<0,0$ & $* * *$ & 0,206 & $<0,0$ & $* * *$ & & & $* * *$ & 0,211251 & & $* * *$ & 0,232997 & & \\
\hline A35 & $-0,0665088$ & 0,00 & $* * *$ & $-0,0960$ & $<0,0$ & $* * *$ & $-0,0753852$ & $<0,0$ & $* * *$ & $-0,0795062$ & $<0$, & $* * *$ & $-0,0631772$ & & \\
\hline$A 37$ & & $<0,0001$ & $* * *$ & 0,273 & $<0,0001$ & $* * *$ & 0,306128 & $<0,($ & *** & 0,300994 & $<0$, & $* * *$ & 0,30548 & & $* *$ \\
\hline$A 46$ & 18728 & $<0,0001$ & $* * *$ & 0,10 & $<0,0001$ & $* * *$ & 9904869 & $<0,0$ & $* * *$ & 0508 & $<0$, & $* * *$ & 0,0621947 & & $* *$ \\
\hline$A 47$ & 0,096362 & 0,0201 & $* *$ & 0,168 & $<0,0001$ & $* * *$ & 116663 & $<0,0$ & $* * *$ & 29266 & $<0$, & $* * *$ & 0,119997 & & $* * *$ \\
\hline$A 52$ & $-0,06>2924$ & 0,0045 & $* * *$ & 0,133505 & $<0,0001$ & *** & $-0,072698$ & $<0,0$ & $* * *$ & $-0,082215$ & $<0,0$ & $* * *$ & $-0,0822811$ & & $* *$ \\
\hline$A 53$ & 0,292701 & $<0,0$ & $* * *$ & 0,276 & & $* * *$ & 26558 & & $* * *$ & 7027 & & $* * *$ & 0,299345 & & $* *$ \\
\hline$A 59$ & $-0,01 \$ 59627$ & 0,0827 & $*$ & $-\phi, 0308628$ & & **** & $-0,013922$ & & $*$ & $-0,016321$ & 0,0275 & $* *$ & $-0,01\{7805$ & 0,0028 & \\
\hline$A 23(-1)$ & $-0,00 \mid 94124$ & 0,4655 & & & & & & & & & & & & & \\
\hline
\end{tabular}

Figure 2. Synthesis of the main results of the panel data regressions. Source of data: European Innovation Scoreboard.

But if we take the mean of the coefficient for the five panel data models proposed we can observe the presence of the following characteristics:

- The three main variables that have a positive impact on human resources are "New Doctorate Graduates" with a mean value of 0,3, "Tertiary Education" with 0,28 and "Life Long Learning" with 0,21;

- The presence of an industrial and manufacturing sector that promote knowledge intensive products and services has a moderate positive impact on the increasing of "Human Resources" with a level comprehended between 1,71 and 1,19;

- The promotion of an education on entrepreneurship in schools has a low positive impact on "Human Resources" with a level equal to 1,261 ; 
- The public and private investment in Research and Development has a low positive effect on "Human Resources" with a degree between 0,092 and 0,12;

- Government procurement of advanced technology product, among the variables that have a negative impact on "Human Resources" is that that have the worst effect on the independent variable with a mean value of $-0,45$.

\section{Ranking of the variables based on the mean value of the coefficient computed with the 5 panel data techniques proposed in the model.}

\begin{tabular}{|c|c|c|c|}
\hline Rank & Variables & Mean & Impact \\
\hline 1 & New doctorate graduates & 0,3014 & \multirow{8}{*}{ Positive } \\
\hline 2 & Tertiary education & 0,2803 & \\
\hline 3 & Lifelong learning & 0,2124 & \\
\hline 4 & Employment MHT manufacturing KIS services & 0,1977 & \\
\hline 5 & Employment share Manufacturing & 0,1719 & \\
\hline 6 & Basic-school entrepreneurial education and training & 0,1633 & \\
\hline 7 & R\&D expenditure public sector & 0,1261 & \\
\hline 8 & $R \& D$ expenditure business sector & 0,0925 & \\
\hline 9 & Venture capital & $-0,0179$ & \multirow{4}{*}{ Negative } \\
\hline 10 & Medium and high-tech product exports & $-0,0765$ & \\
\hline 11 & SMEs innovating in-house & $-0,0876$ & \\
\hline 12 & Government procurement of advanced technology products & $-0,4584$ & \\
\hline
\end{tabular}

Figure 3. Ranking of the variables based on the mean value of the coefficient computed with the 5 panel data techniques proposed in the model. Source: European Innovation Scoreboard.

\section{Clusterization}

Using the software Orange, we have performed a clusterization through the algorithm k-means and tSNE. We choose the efficient number of clusters using the Silhouette coefficient for the year 2021. We found three different typologies of clusters:

- Cluster 1: Denmark, Finland, Norway, Sweden, Switzerland and United Kingdom;

- Cluster 2: Bosnia and Herzegovina, Bulgaria, Croatia, Czechia, Greece, Hungary, Italy, Latvia, Malta, Montenegro, North Macedonia, Poland, Portugal, Romania, Serbia, Slovakia, Turkey, Ukraine;

- Cluster 3: Austria, Belgium, Cyprus, Estonia, France, Germany, Iceland, Ireland, Israel, Lithuania, Luxembourg; Netherlands, Slovenia, Spain.

In terms of value cluster 1 is the more efficient in the sense of Human Resources with a mean value of 187 followed by the Cluster 3 with a mean of 136. Cluster 2 closes the ranking with a mean level of Human Resources equal to 56,00 . 


\begin{tabular}{|c|c|c|c|c|}
\hline \multicolumn{5}{|c|}{$\begin{array}{c}\text { Characteristics of the Clusters for Level of Human Resources in } \\
2021 \text { in European Countries. Source: European Innovation } \\
\text { Scoreboard. }\end{array}$} \\
\hline Rank & Clusters & Mean Value & Min & Max \\
\hline 1 & Cluster 1 & 187,00 & 163,00 & 222,61 \\
\hline 3 & Cluster 2 & 56,00 & 8,95 & 100,26 \\
\hline 2 & Cluster 3 & 136,00 & 104,11 & 180,77 \\
\hline
\end{tabular}

Figure 4. Characteristics of the Clusters for the level of Human Resources in 2021 in European Countries. Source: European Innovation Scoreboard.

Our results show that the half of countries analyzed in the European Innovation Scoreboard have a low level of Human Resources that can be considered insufficient to sustain an effective process of production of innovation technology. The Cluster 2 has a level of mean value of human resources that is equal 70\% lower than Cluster 1 and 59\% lower that cluster 3. These differences cannot be solved in the short run and require long run investment in education, Research and Development, and entrepreneurship to promote a convergence of the values of countries in Cluster 2 towards the levels of countries in clusters 1 and 3 .

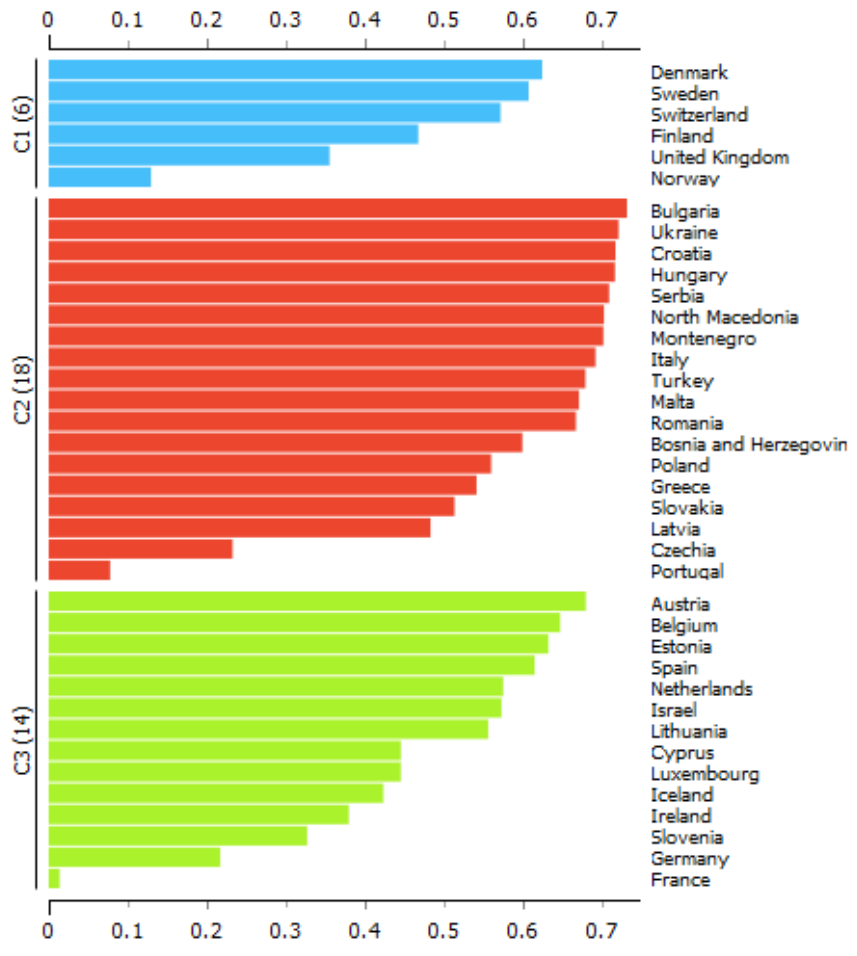

Figure 5. Clusterization of European Countries in 2021 based on the level of Human Resources. Source: European Innovation Scoreboard. Tool: Orange. Algorithm: k-Means. Optimization: Silhouette Coefficient.

We can also observe that countries in the Cluster 1 and in the Cluster 2 that have the higher levels of "Human Resources" also have higher levels of Gross Domestic Products. While countries in the Clusters 3, i.e., Italy, Portugal and Eastern Europe countries have lower levels of income per capita in respect of countries in Clusters 1 and 2. These considerations can reinforce the idea that Human Resources is a significant driver for economic growth measured in terms of GDP per capita. European policy makers that are interested in promoting a deeper economic growth among European countries 
and in southern and eastern Europe should promote an improve in policies able to finance "New Doctorate", "Lifelong Learning" and "Tertiary Education".

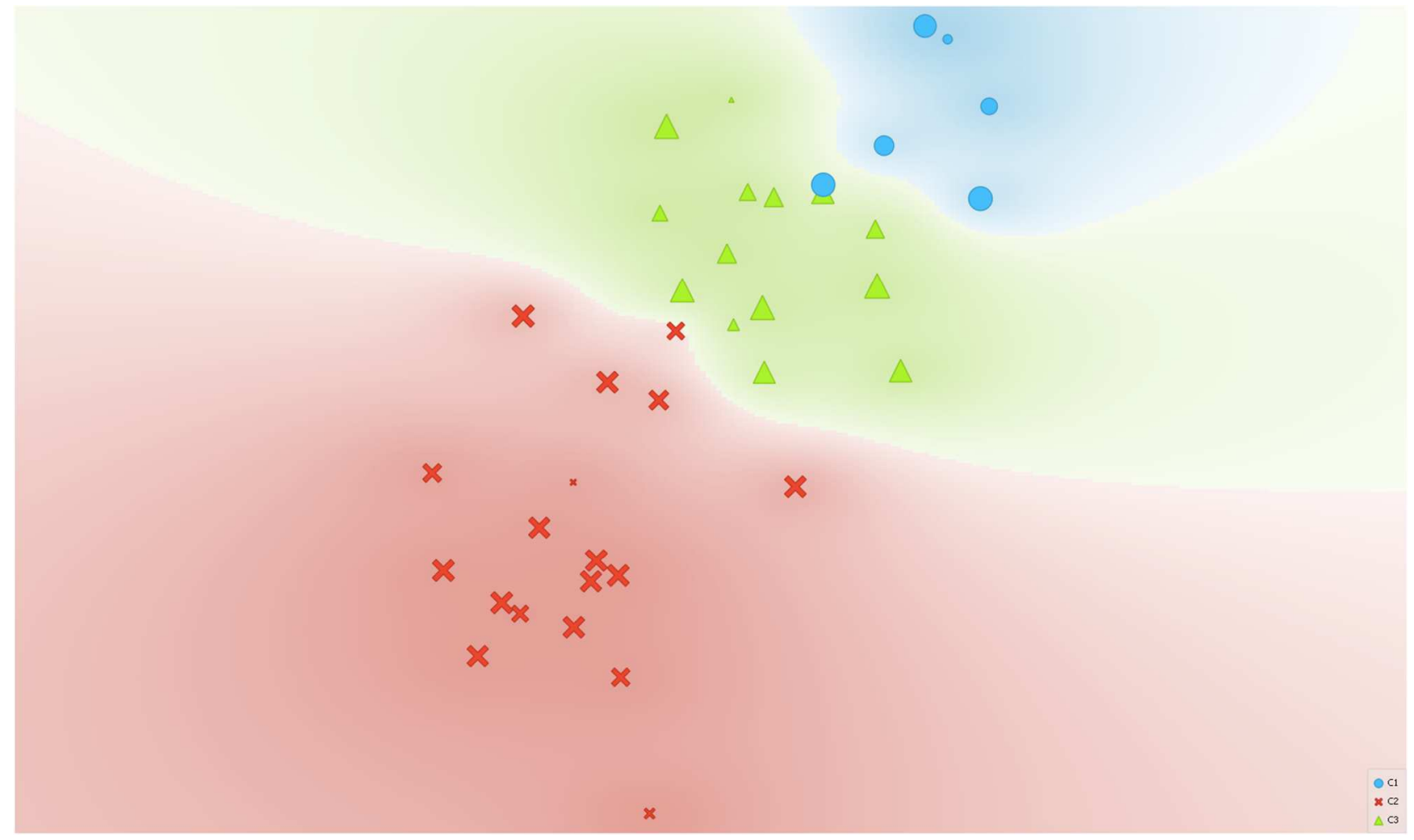

Figure 6. Representation of the clusterization with the algorithm t-SNE. Tool: Orange. Source: European Innovation Scoreboard. Year: 2021.

Finally, we can conclude that there is a great gap between countries in the Cluster 3 and countries in Clusters 1 and 2. The gap impedes to many countries in southern and eastern Europe to have access to the knowledge society, the knowledge economy and to develop firms and institutions able to sustain the growing servitization of the production processes at a corporate level. The economics of intangibles, of intellectual property rights and of immaterial assets based on the valuation of human capital is not feasible for at least 18 European countries. This gap creates new inequalities and can have a long run effect on the perspective of economic growth for medium and low income countries in Europe.

\section{Machine Learning and Predictions}

We have also performed a form of machine learning and prediction with the sequent models:

- Linear Regression;

- Tree Ensemble Regression;

- Polynomial Regression;

- Artificial Neural Network-ANN;

- Gradient Boosted Trees;

- Random Forest Regression;

- Probabilistic Neural Networks-PNN.

Our goal is to estimate the value of Human Resources using the historical series of the European Innovation Scoreboard in the period 2014-2021 using KNIME to find the best predictor algorithm. 
We divide the data in two partitions using the KNIME node "Partitioning" with a $70 \%$ of training data and the remaining $30 \%$ of test data. To evaluate the best predictor algorithm, we have computed a maximization of R-squared and the minimization of the following errors:

- Mean Absolute Error;

- Mean Squared Error;

- Root Mean Squared Error;

- Mean Signed Difference.

\begin{tabular}{l|l|r|r|r|r|r|}
\hline \multicolumn{7}{c|}{ Machine Learning and Prediction of Human Resources in Europe. Source: European Innovation Scoreboard. } \\
\hline & $R^{\wedge} \mathbf{2}$ & Mean Absolute Error & Mean Squared Error & Root Mean Squared Error & Mean Signed Difference \\
\hline ANN & 0,9626 & 0,0370 & 0,0030 & 0,0552 & 0,0226 \\
\hline PNN & 0,8853 & 0,0622 & 0,0046 & 0,0679 & 0,0114 \\
\hline GRADIENT BOOSTED TREES & 0,9036 & 0,0492 & 0,0039 & 0,0623 & 0,0016 \\
\hline RANDOM FOREST REGRESSION & 0,9380 & 0,0532 & 0,0039 & 0,0625 & 0,0093 \\
\hline TREE ENSEMBLE REGRESSION & 0,9569 & 0,0364 & 0,0018 & 0,0420 & 0,0010 \\
\hline LINEAR REGRESSION & 0,9787 & 0,0270 & 0,0011 & 0,031 & 0,0078 \\
\hline POLYNOMIAL REGRESSION & 0,9681 & 0,0396 & 0,0019 & 0,0047 \\
\hline
\end{tabular}

Figure 7. Results of the Machine Learning and Prediction Algorithms using KNIME.

\section{Machine Learning and Prediction of Human Resources in Europe. Source: European Innovation Scoreboard.}

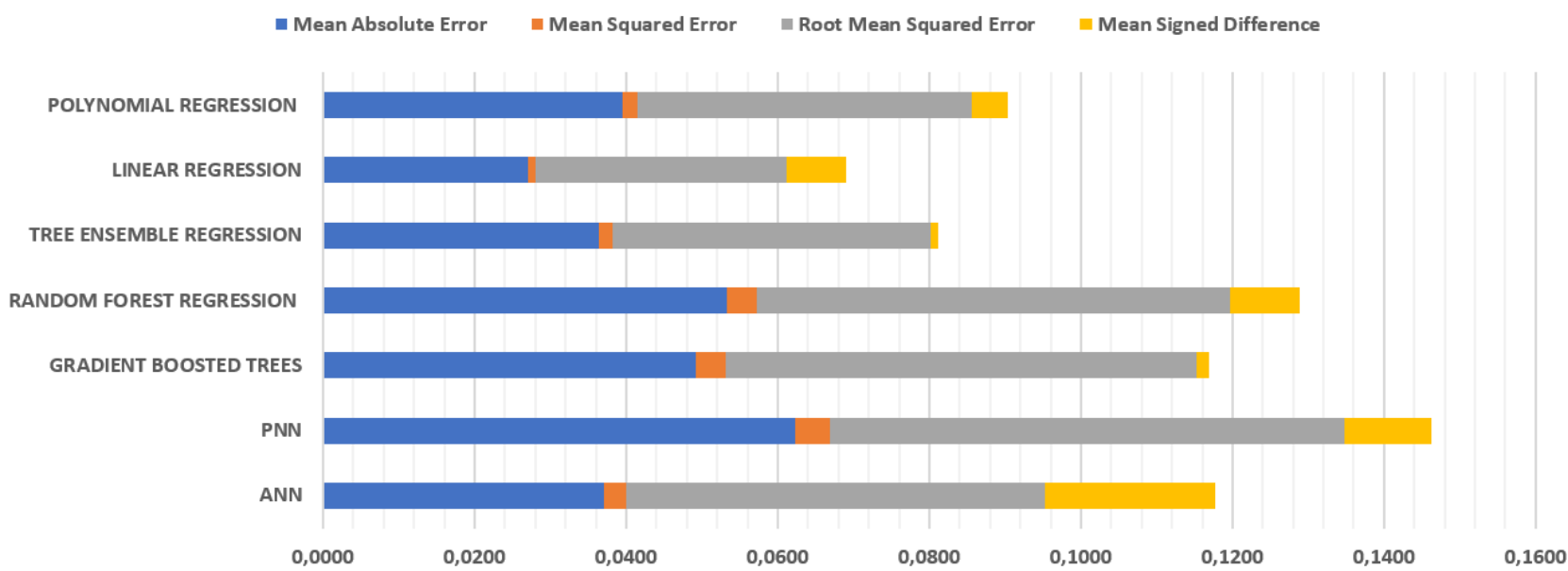

Figure 8. Results of Machine Learning and Prediction Algorithms using KNIME. Linear Regression, in the combination of learner and prediction, has the lower values of estimated errors.

We found that the best predictor algorithm is the linear regression followed in order by Tree Ensemble Regression, Polynomial Regression, Artificial Neural Network ${ }^{4}$-ANN, Gradient Boosted Trees, Random Forest Regression and Probabilistic Neural Network-PNN.

\section{Conclusions}

In this article we have estimated the innovational determinants of human resources. We perform five different panel data model i.e., Panel Data with Fixed Effects, Panel Data with Random Effects, Dynamic Panel Data, Pooled OLS, WLS. Data are collected from the European Innovation Scoreboard for 36 European countries in the period 2010-2019. We found that the level of human resources is positively and primarily associated to variables associated to instruction such as: lifelong learning, new doctorates, and tertiary education. The clusterization analysis realized with the k-Means

\footnotetext{
${ }^{4}$ The hyperparameters of Artificial Neural Network-ANN MLP are: the maximum number of iterations is equal to 100, the number of hidden layers is equal to 1 , the number of hidden neurons per layer is equal to 10 .
} 
algorithm, optimized with the Silhouette coefficient, shows the presence of three different clusters in Europe. The first cluster represents the Northern European countries with higher levels of human resources, followed by Central European Countries with lower levels of huma resources in respect to cluster 1, while the third cluster contains Southern and Eastern European Countries show very low levels of human resources either in respect to cluster 2 either to cluster 1. Finally, we use seven different machine learning algorithms to predict the level of human resources based on data in the period 2014-2021. We show that the linear regression algorithm is the best predictor of the level of human resources in the sense of minimization of errors and maximization of R-squared. Finally, we can conclude that the level of human resources is an essential input of the innovation technology and of the Research and Development activities either at a national either at a corporate level. As the clusterization analysis has clearly showed there is an evident gap between Central-Northern European countries and Southern-Eastern European countries. As our econometric model shows, policy makers can improve the level of human resources, through the investment in lifelong learning, tertiary education, and new doctorates. In the end, machine learning algorithms can be used to efficiently predict the level of human resources as a target for political economies oriented to growth and development.

\section{Bibliography}

[1] R. M. Solow, «A Contribution to the Theory of Economic Growth,» The Quarterly Journal of Economics, vol. 70, n. 1, pp. 65-94, 1956.

[2] P. M. Romer, «The Origins of Endogenous Growth,» Journal of Economic Perspectives, vol. 8, n. 1, pp. 3-22, 1994.

[3] J. A. Schumpeter, The Theory of Economic Development: an Inquiry into Profits, Capital, Credit, Interest, and the Business Cycle, New Brunswick: Transaction Books, 1934.

[4] A. Leogrande, A. Massaro e A. M. Galiano, «The Determinants of Human Resources in European Countries During the Period 2010-2019,» American Journal of Humanities and Social Sciences Research (AJHSSR), vol. 4, n. 9, pp. 145-171, 2020.

[5] A. Costantiello, L. Laureti, G. De Cristoforo e A. Leogrande, «The Innovation-Sales Growth Nexus in Europe,» University Library of Munich, Germany, 2021.

[6] A. Costantiello, L. Laureti e A. Leogrande, «The Determinants of Firm Investments in Research and Development,» in International Virtual Academic Conference Education and Social Sciences Business and Economics, Online, 2021.

[7] A. Costantiello, L. Laureti e A. Leogrande, «The SMEs Innovation in Europe,» in FEMIB, Online , 2021.

[8] L. Laureti, A. Costantiello e L. Leogrande, «The Finance-Innovation Nexus in Europe,» IJISET - International Journal of Innovative Science, Engineering \& Technology, vol. 7, n. 12, pp. 11-55, 2020. 
[9] A. Costantiello e A. Leogrande, «The innovation-employment nexus in Europe,» American Journal of Humanities and Social Sciences Research (AJHSSR), vol. 4, n. 11, pp. 166-187, 2020.

[10] A. Leogrande, A. Massaro e A. M. Galiano, «The Attractiveness of European Research Systems,» American Journal of Humanities and Social Sciences Research (AJHSSR), vol. 4, n. 10, pp. 72-101, 2020.

[11] A. Leogrande, A. Massaro e A. M. Galiano, «The Impact of R\&D Investments on Corporate Performance in European Countries,» American Journal of Humanities and Social Sciences Research (AJHSSR), vol. 4, n. 7, pp. 186-201, 2020.

[12] A. Costantiello, L. Laureti e A. Leogrande, «The Innovation-Friendly Environment in Europe,» in ICSET- International Conference on Science, Engineering \& Technology, Singapore, 2021.

[13] A. Leogrande, G. Birardi, A. Massaro e A. M. Galiano, «Italian Universities: Institutional Mandate and Communitarian Engagement,» European Journal of Educational Management, vol. 2, n. 2, pp. 85-110, 2019.

[14] F. B. T. Rahim e Y. B. Zainuddin, «The Impact of Technological Innovation Capabilities on Competitive Advantage and Firm Performance in the Automotive Industry in Malaysia,» in AIP Conference Proceedings, 2019.

[15] Y. Balci, «Some Critical Issues in Innovation and Economic Development: Lessons from the Recent Turkish Experience,» Procedia Computer Science, vol. 158, pp. 609-624, 2019.

[16] Z. Znagui e B. Rahmouni, «What Ecosystem Model to Support the Creation of Social Innovation Technopoles?,» Procedia Computer Science, vol. 158, pp. 877-884, 2019.

[17] E. Astuty, A. Rahayu e L. A. Wibowo, «Breakthrough in Indonesian Creative Industry through Soft Innovation,» International Journal of Entrepreneurship, vol. 22, n. 2, pp. 1-10, 2018.

[18] J. Han e C. M. Park, «Case Study on Adoption of New Technology for Innovation: Perspective of institutional and Corporate Entrepreneurship,» Asia Pacific Journal of Innovation and Entrepreneurship, 2017.

[19] A. Beraha, D. Bingol, E. Ozkan-Canbolat e N. Szczygiel, «The Effect of Strategic Flexibility Configurations on Product Innovation,» European Journal of Management and Business Economics, 2018.

[20] L. T. Berampu e W. D. Sari, «Human Resources Transformation in the Digitalization Professional Era in North Sumatera,» Esensi: Jurnal Bisnis Dan Manajemen, vol. 10, n. 2, pp. 135-146, 2020.

[21] C. Capozza e M. Divella, «Human Capital and Firms’ Innovation: Evidence from Emerging Economies,» Economics of Innovation and New Technology, vol. 28, n. 7, pp. 741-757, 2019. 
[22] X. Norasingh e P. Southammavong, «Firm-Level Human Resource Management and Innovation Activities in Production Networks: A Case Study of Lao Handicraft Firms,» Asian Journal of Technology Innovation, vol. 25, n. 2, pp. 288-309, 2017.

[23] T. L. Akpey-Mensah, «Social Capital Development as Innovation in Human Resource Development: A Case of Technical Universities in Ghana,» African Journal of Science, Technology, Innovation and Development, vol. 12, n. 1, pp. 27-32, 2020.

[24] J. C. Canedo, G. Graen, M. Grace e R. D. Johnson, «Navigating the New Workplace: Technology, Millennials, and Accelerating HR Innovation,» AIS Transactions on HumanComputer Interaction, vol. 9, n. 3, pp. 243-260, 2017.

[25] M. Giebel e K. Kraft, «Bank Credit Supply and Firm Innovation,» ZEW-Centre for European Economic Research Discussion Paper, vol. 18, n. 011, 2018.

[26] A. M. Androniceanu, J. Kinnunen, I. Georgescu e A. Androniceanu, «A Multidimensional Approach to Competitiveness, Innovation and Well-Being in the EU Using Canonical Correlation Analysis,» Journal of Competitiveness, vol. 12, n. 4, 2020.

[27] A. V. Mohan, «Human Resource Management and Coordination for Innovation Activities: Gleanings from Malaysian Cases,» Asian Journal of Technology Innovation, vol. 25, n. 2, pp. 246-267, 2017.

\section{Appendix}

\subsection{Regression Results with Gretl}

\begin{tabular}{|c|l|l|l|}
\hline \multicolumn{2}{|c|}{ Variables } & Label & \\
\hline $\boldsymbol{y}$ & Human Resources & $A 23$ & \\
\hline $\boldsymbol{x}_{\mathbf{1}}$ & Basic-school entrepreneurial education and training (SD) & $A 4$ & + \\
\hline $\boldsymbol{x}_{\mathbf{2}}$ & Employment MHT manufacturing KIS services & $A 11$ & + \\
\hline $\boldsymbol{x}_{\mathbf{3}}$ & Employment share Manufacturing (SD) & $A 12$ & + \\
\hline $\boldsymbol{x}_{\mathbf{4}}$ & Government procurement of advanced technology products (SD) & $A 22$ & - \\
\hline $\boldsymbol{x}_{\mathbf{5}}$ & Lifelong learning & $A 32$ & + \\
\hline $\boldsymbol{x}_{\mathbf{6}}$ & Medium and high-tech product exports & $A 35$ & - \\
\hline $\boldsymbol{x}_{\mathbf{7}}$ & New doctorate graduates & $A 37$ & + \\
\hline $\boldsymbol{x}_{\mathbf{8}}$ & R\&D expenditure business sector & $A 46$ & + \\
\hline $\boldsymbol{x}_{\mathbf{9}}$ & R\&D expenditure public sector & $A 47$ & + \\
\hline $\boldsymbol{x}_{\mathbf{1 0}}$ & SMEs innovating in-house & $A 52$ & - \\
\hline $\boldsymbol{x}_{\mathbf{1 1}}$ & Tertiary education & $A 53$ & + \\
\hline $\boldsymbol{x}_{\mathbf{1 2}}$ & Venture capital & $A 59$ & - \\
\hline
\end{tabular}




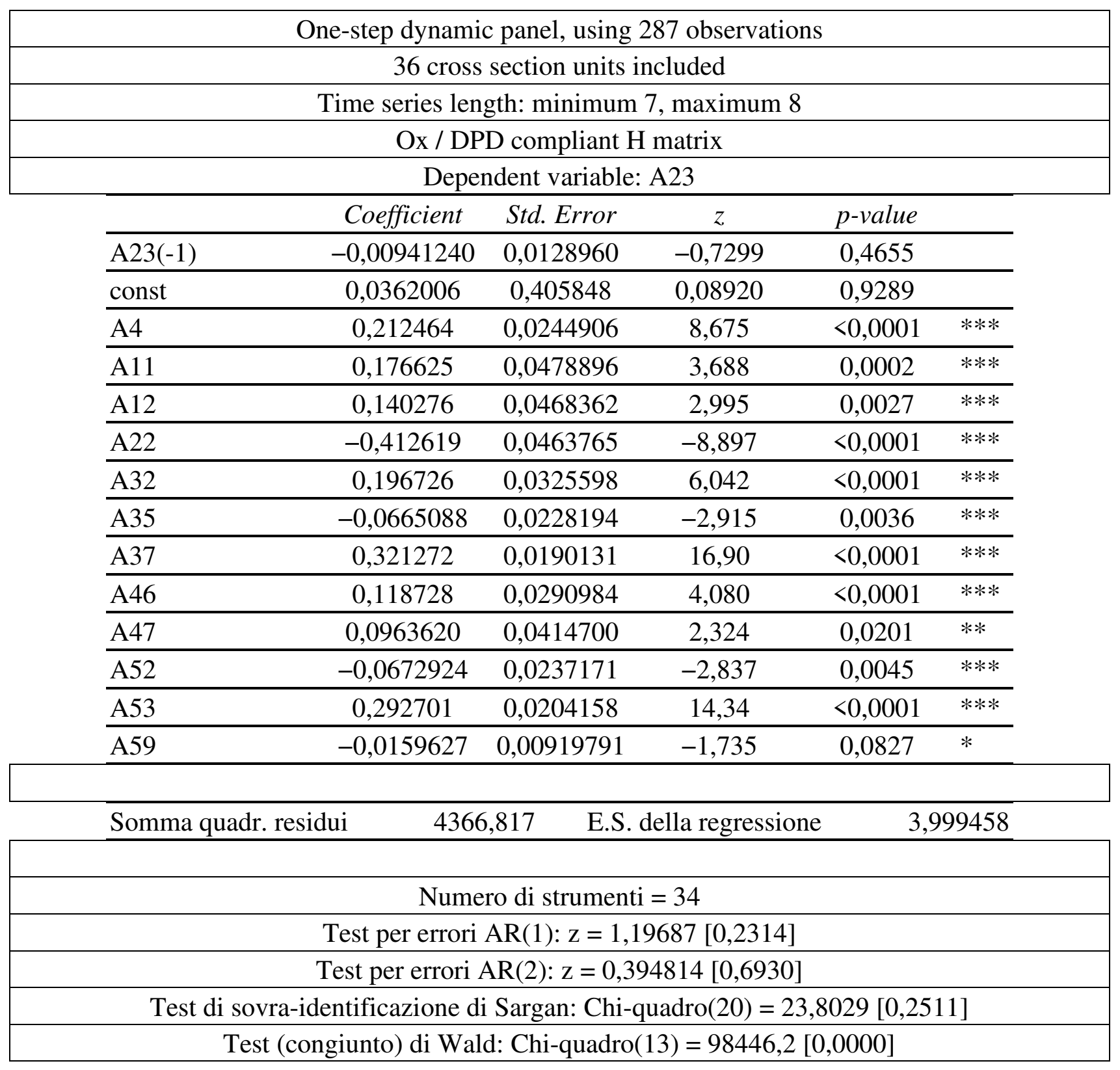




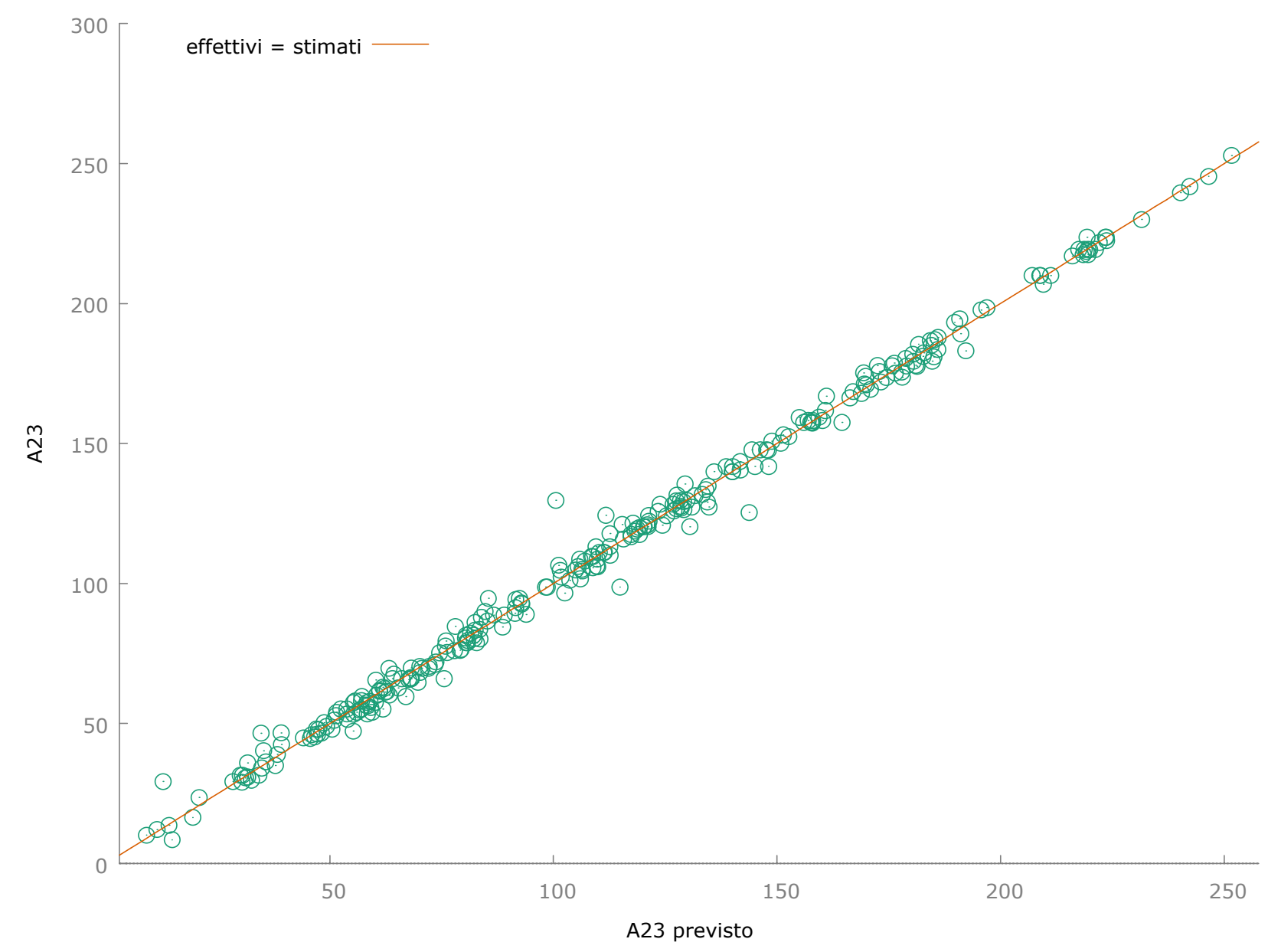

Pooled OLS, usando 358 osservazioni Incluse 36 unità cross section

Lunghezza serie storiche: minimo 8, massimo 10 Variabile dipendente: A23

\begin{tabular}{lccccc}
\hline & Coefficiente & Errore Std & rapporto $t$ & $p$-value & \\
\hline const & 1,66348 & 0,764518 & 2,176 & 0,0302 & $* *$ \\
\hline A4 & 0,151388 & 0,0163032 & 9,286 & $<0,0001$ & $* * *$ \\
\hline \hline A11 & 0,235696 & 0,0112219 & 21,00 & $<0,0001$ & $* * *$ \\
\hline A12 & 0,260197 & 0,0342445 & 7,598 & $<0,0001$ & $* * *$ \\
\hline A22 & $-0,534613$ & 0,0327173 & $-16,34$ & $<0,0001$ & $* * *$ \\
\hline A32 & 0,206297 & 0,00871573 & 23,67 & $<0,0001$ & $* * *$ \\
\hline A35 & $-0,0960481$ & 0,0114040 & $-8,422$ & $<0,0001$ & $* * *$ \\
\hline A37 & 0,273373 & 0,0116970 & 23,37 & $<0,0001$ & $* * *$ \\
\hline A46 & 0,101147 & 0,0164290 & 6,157 & $<0,0001$ & $* * *$ \\
\hline A47 & 0,168065 & 0,0163044 & 10,31 & $<0,0001$ & $* * *$ \\
\hline A52 & $-0,133505$ & 0,0128597 & $-10,38$ & $<0,0001$ & $* * *$ \\
\hline A53 & 0,276928 & 0,00810929 & 34,15 & $<0,0001$ & $* * *$ \\
\hline A59 & $-0,0308628$ & 0,00807233 & $-3,823$ & 0,0002 & $* * *$ \\
\hline
\end{tabular}




\begin{tabular}{lrll}
\hline Media var. dipendente & 91,00458 & SQM var. dipendente & 68,04448 \\
\hline Somma quadr. residui & 18989,27 & E.S. della regressione & 7,418986 \\
\hline R-quadro & 0,988512 & R-quadro corretto & 0,988112 \\
\hline F(12, 345) & 2473,805 & P-value(F) & 0,000000 \\
\hline Log-verosimiglianza & $-1218,806$ & Criterio di Akaike & 2463,612 \\
\hline Criterio di Schwarz & 2514,059 & Hannan-Quinn & 2483,675 \\
\hline \hline rho & 0,900327 & Durbin-Watson & 0,327024 \\
\hline
\end{tabular}

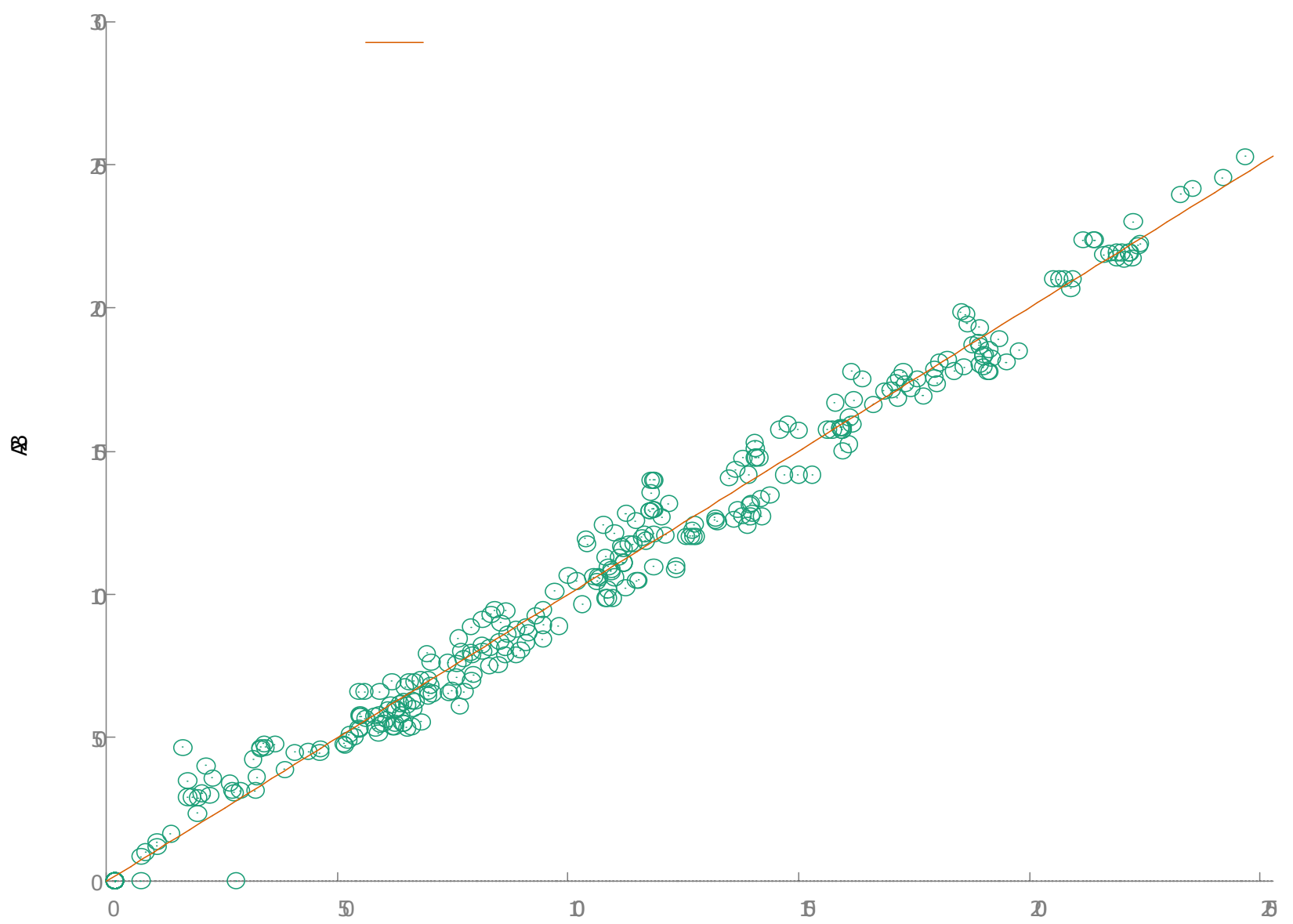

Effetti fissi, usando 358 osservazioni

Incluse 36 unità cross section

Lunghezza serie storiche: minimo 8, massimo 10

Variabile dipendente: A23

\begin{tabular}{lccccc}
\hline & Coefficiente & Errore Std & rapporto $t$ & $p$-value & \\
\hline const & 0,174644 & 0,568338 & 0,3073 & 0,7588 & \\
\hline A4 & 0,131767 & 0,0226674 & 5,813 & $<0,0001$ & $* * *$ \\
\hline A11 & 0,209329 & 0,0135921 & 15,40 & $<0,0001$ & $* * *$ \\
\hline
\end{tabular}




\begin{tabular}{lccccc}
\hline A12 & 0,142652 & 0,0339725 & 4,199 & $<0,0001$ & $* * *$ \\
\hline \hline A22 & $-0,464164$ & 0,0401838 & $-11,55$ & $<0,0001$ & $* * *$ \\
\hline A32 & 0,214497 & 0,0110444 & 19,42 & $<0,0001$ & $* * *$ \\
\hline A35 & $-0,0753852$ & 0,0145905 & $-5,167$ & $<0,0001$ & $* * *$ \\
\hline \hline A37 & 0,306128 & 0,0134557 & 22,75 & $<0,0001$ & $* * *$ \\
\hline A46 & 0,0904869 & 0,0181675 & 4,981 & $<0,0001$ & $* * *$ \\
\hline A47 & 0,116663 & 0,0194239 & 6,006 & $<0,0001$ & $* * *$ \\
\hline A52 & $-0,0726980$ & 0,0140301 & $-5,182$ & $<0,0001$ & $* * *$ \\
\hline A53 & 0,265580 & 0,0102251 & 25,97 & $<0,0001$ & $* * *$ \\
\hline A59 & $-0,0139220$ & 0,00744774 & $-1,869$ & 0,0625 & $*$ \\
\hline
\end{tabular}

\begin{tabular}{lcll}
\hline Media var. dipendente & 91,00458 & SQM var. dipendente & 68,04448 \\
\hline Somma quadr. residui & 7728,774 & E.S. della regressione & 4,993148 \\
\hline R-quadro LSDV & 0,995324 & R-quadro intra-gruppi & 0,991706 \\
\hline LSDV F(47, 310) & 1404,015 & P-value(F) & 0,000000 \\
\hline Log-verosimiglianza & $-1057,899$ & Criterio di Akaike & 2211,798 \\
\hline Criterio di Schwarz & 2398,063 & Hannan-Quinn & 2285,876 \\
\hline rho & 0,601889 & Durbin-Watson & 0,624058 \\
\hline
\end{tabular}

Test congiunto sui regressori -

Statistica test: $F(12,310)=3088,84$

con $\mathrm{p}$-value $=\mathrm{P}(\mathrm{F}(12,310)>3088,84)=0$

Test per la differenza delle intercette di gruppo -

Ipotesi nulla: i gruppi hanno un'intercetta comune

Statistica test: $F(35,310)=12,9045$

con $\mathrm{p}$-value $=\mathrm{P}(\mathrm{F}(35,310)>12,9045)=2,369 \mathrm{e}-042$ 


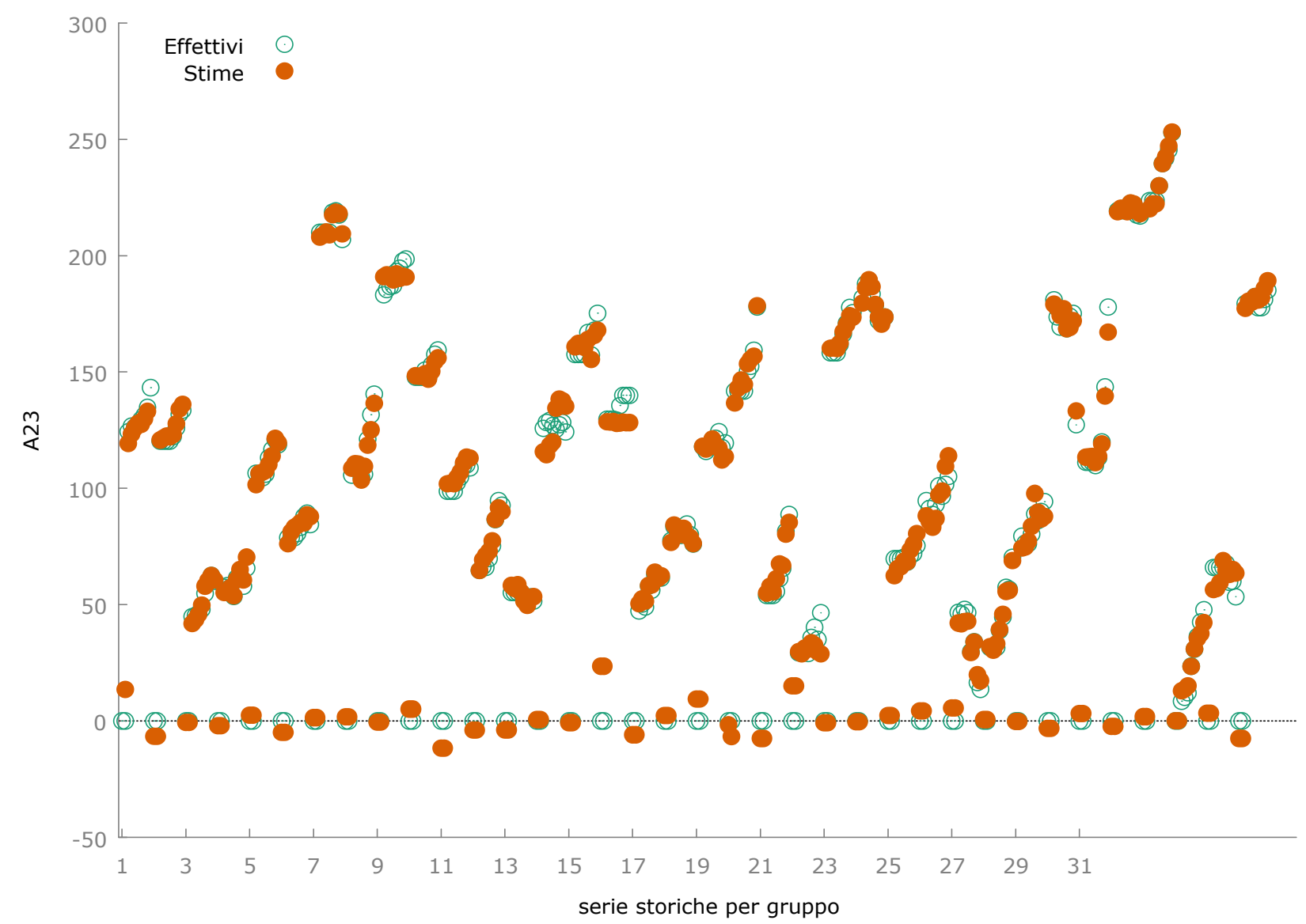

\begin{tabular}{|c|c|c|c|c|c|}
\hline \multicolumn{6}{|c|}{ Effetti casuali (GLS), usando 358 osservazioni } \\
\hline \multicolumn{6}{|c|}{ Incluse 36 unità cross section } \\
\hline \multicolumn{6}{|c|}{ Lunghezza serie storiche: minimo 8 , massimo 10} \\
\hline \multicolumn{6}{|c|}{ Variabile dipendente: A23 } \\
\hline & Coefficiente & Errore Std. & $z$ & $p$-value & \\
\hline const & 0,258045 & 1,14649 & 0,2251 & 0,8219 & \\
\hline A4 & 0,136655 & 0,0206005 & 6,634 & $<0,0001$ & $* * *$ \\
\hline A11 & 0,215103 & 0,0126609 & 16,99 & $<0,0001$ & $* * *$ \\
\hline A12 & 0,159500 & 0,0327649 & 4,868 & $<0,0001$ & **** \\
\hline A22 & $-0,470201$ & 0,0371905 & $-12,64$ & $<0,0001$ & **** \\
\hline A32 & 0,211251 & 0,0101975 & 20,72 & $<0,0001$ & $* * *$ \\
\hline $\mathrm{A} 35$ & $-0,0795062$ & 0,0134161 & $-5,926$ & $<0,0001$ & $* * *$ \\
\hline A37 & 0,300994 & 0,0127179 & 23,67 & $<0,0001$ & $* * *$ \\
\hline$\overline{\mathrm{A} 46}$ & 0,0900508 & 0,0172099 & 5,233 & $<0,0001$ & $* * *$ \\
\hline$\overline{\mathrm{A} 47}$ & 0,129266 & 0,0181918 & 7,106 & $<0,0001$ & $* * *$ \\
\hline$\overline{\mathrm{A} 52}$ & $-0,0822150$ & 0,0133824 & $-6,144$ & $<0,0001$ & $* * *$ \\
\hline A53 & 0,267027 & 0,00944962 & 28,26 & $<0,0001$ & $* * *$ \\
\hline A59 & $-0,0160321$ & 0,00727203 & $-2,205$ & 0,0275 & $* *$ \\
\hline
\end{tabular}




\begin{tabular}{|c|c|c|c|}
\hline Media var. dipendente & 91,00458 & SQM var. dipendente & 68,04448 \\
\hline Somma quadr. residui & 21608,36 & E.S. della regressione & 7,902652 \\
\hline Log-verosimiglianza & $-1241,934$ & Criterio di Akaike & 2509,868 \\
\hline $\begin{array}{l}\text { Criterio di Schwarz } \\
\end{array}$ & 2560,315 & Hannan-Quinn & 2529,931 \\
\hline rho & 0,601889 & Durbin-Watson & 0,624058 \\
\hline \multicolumn{4}{|c|}{ Varianza 'between' = 35,369 } \\
\hline \multicolumn{4}{|c|}{ Varianza 'within' $=24,9315$} \\
\hline \multicolumn{4}{|c|}{ theta medio $=0,742614$} \\
\hline \multicolumn{4}{|c|}{ Test congiunto sui regressori - } \\
\hline \multicolumn{4}{|c|}{ Statistica test asintotica: Chi-quadro $(12)=38525,6$} \\
\hline \multicolumn{4}{|c|}{ con p-value $=0$} \\
\hline \multicolumn{4}{|l|}{ Test Breusch-Pagan - } \\
\hline \multicolumn{4}{|c|}{ Ipotesi nulla: varianza dell'errore specifico all'unità $=0$} \\
\hline \multicolumn{4}{|c|}{ Statistica test asintotica: Chi-quadro $(1)=340,788$} \\
\hline \multicolumn{4}{|c|}{ con p-value $=4,29828 \mathrm{e}-076$} \\
\hline \multicolumn{4}{|c|}{ Test di Hausman - } \\
\hline \multicolumn{4}{|c|}{ Ipotesi nulla: le stime GLS sono consistenti } \\
\hline \multicolumn{4}{|c|}{ Statistica test asintotica: Chi-quadro $(12)=16,8662$} \\
\hline con $p$-value $=0,154702$ & & & \\
\hline
\end{tabular}




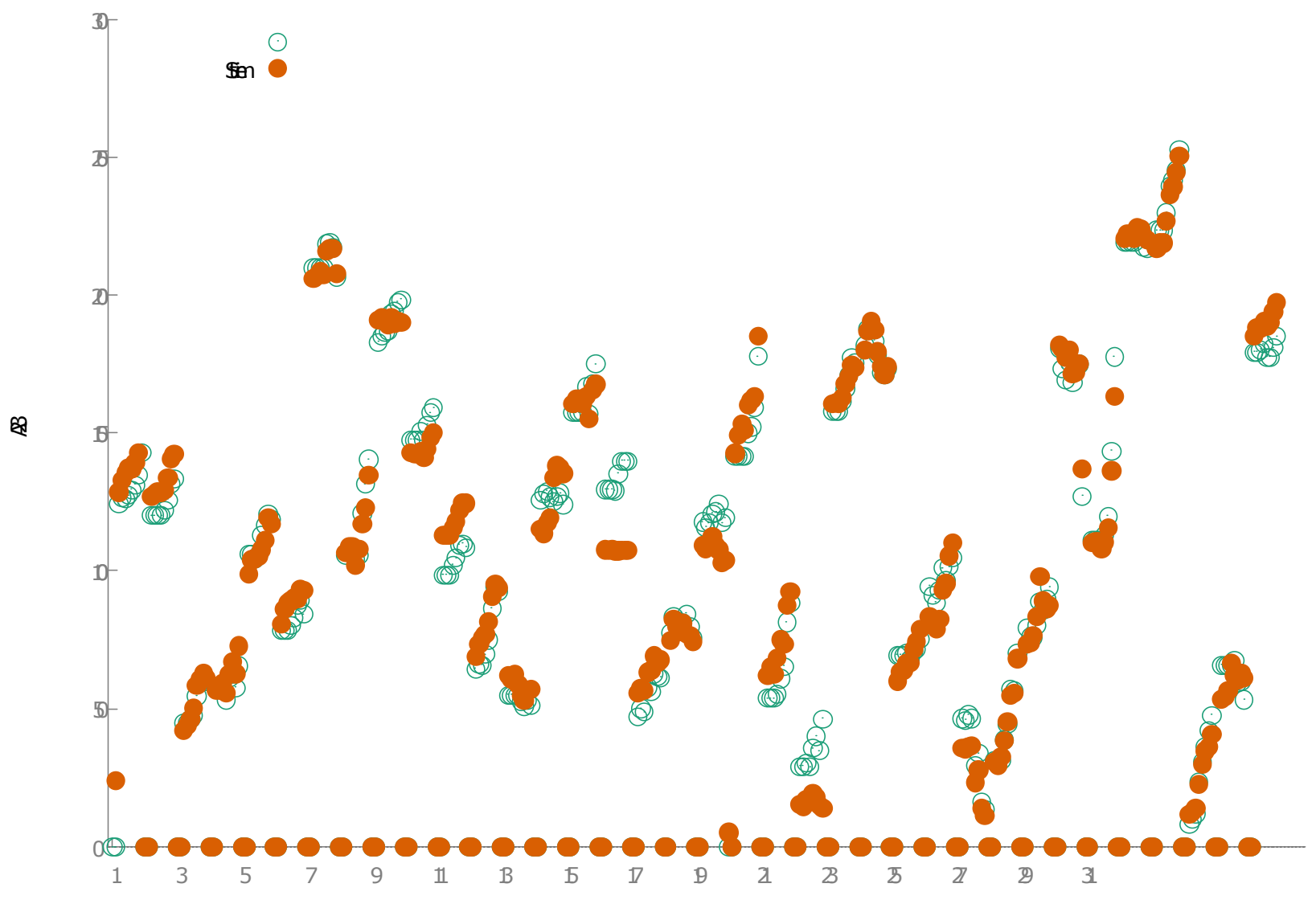

Modello 70: WLS, usando 358 osservazioni Incluse 36 unità cross section

Variabile dipendente: A23

Pesi basati sulle varianze degli errori per unità

$\begin{array}{lccccl}\text { const } & 0,164731 & 0,386516 & 0,4262 & 0,6702 & \\ \text { A4 } & 0,184460 & 0,0127293 & 14,49 & <0,0001 & * * * \\ \text { A11 } & 0,151996 & 0,00967149 & 15,72 & <0,0001 & * * * \\ \text { A12 } & 0,157114 & 0,0250899 & 6,262 & <0,0001 & * * * \\ \text { A22 } & -0,410288 & 0,0243232 & -16,87 & <0,0001 & * * * \\ \text { A32 } & 0,232997 & 0,00580705 & 40,12 & <0,0001 & * * * \\ \text { A35 } & -0,0651772 & 0,00660499 & -9,868 & <0,0001 & * * * \\ \text { A37 } & 0,305480 & 0,00730008 & 41,85 & <0,0001 & * * * \\ \text { A46 } & 0,0621947 & 0,00981435 & 6,337 & <0,0001 & * * * \\ \text { A47 } & 0,119997 & 0,0104281 & 11,51 & <0,0001 & * * * \\ \text { A52 } & -0,0822811 & 0,00758662 & -10,85 & <0,0001 & * * * \\ \text { A53 } & 0,299345 & 0,00495578 & 60,40 & <0,0001 & * * * \\ \text { A59 } & -0,0127805 & 0,00424777 & -3,009 & 0,0028 & * * *\end{array}$

Statistiche basate sui dati ponderati:

Somma quadr. residui R-quadro
248,9142 E.S. della regressione 0,997747 R-quadro corretto 
$\mathrm{F}(12,345)$

12733,68

P-value(F)

0,000000

Log-verosimiglianza

$-442,9270$

Criterio di Akaike

911,8540

Criterio di Schwarz

962,3009

Hannan-Quinn

931,9168

Statistiche basate sui dati originali:

Media var. dipendente

91,00458

SQM var. dipendente

68,04448

Somma quadr. residui

30178,93

E.S. della regressione

A23: valori effettivi e stimati

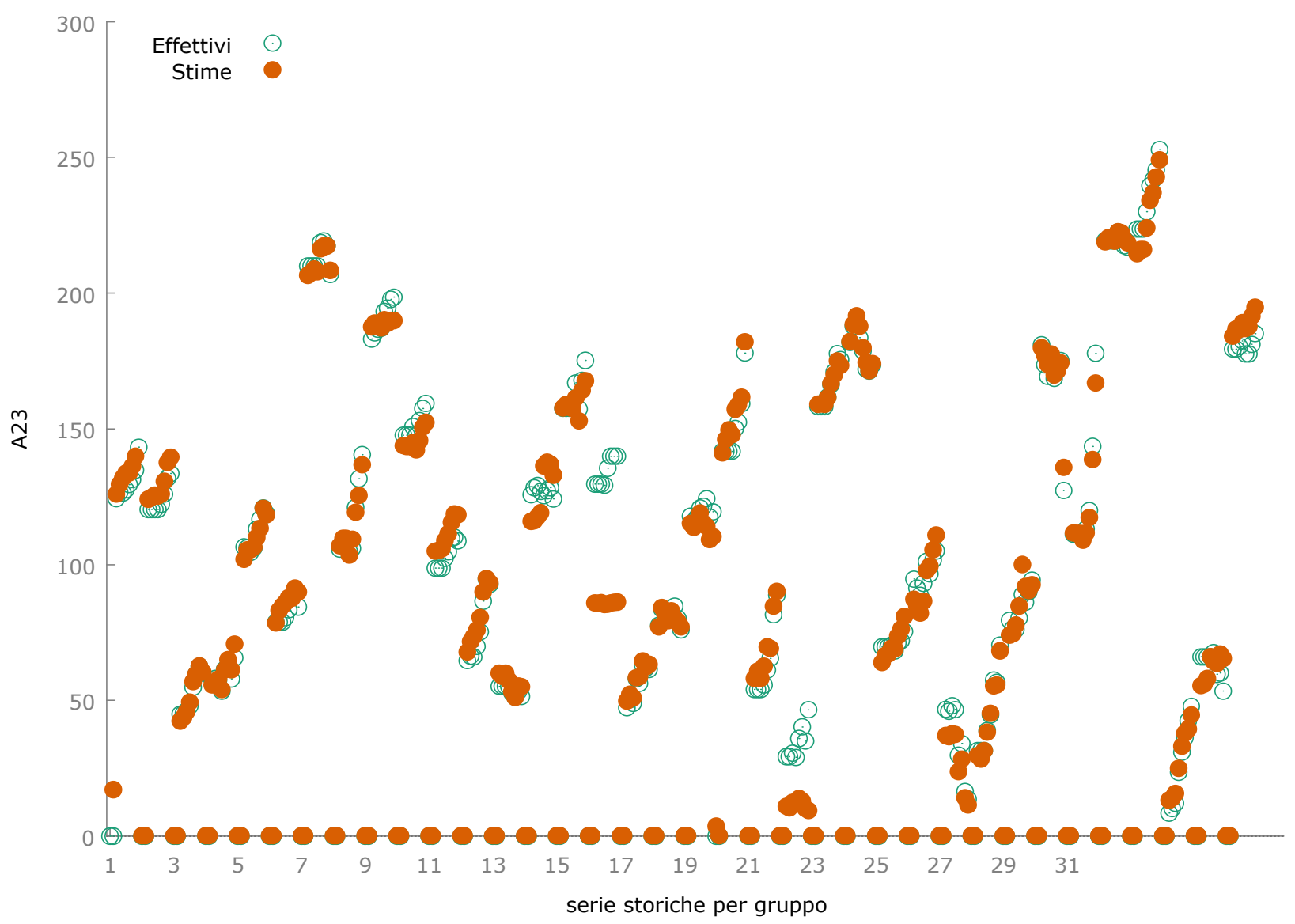

\subsection{Clusterization Results with Orange}




\begin{tabular}{|c|c|c|}
\hline Feature 1 & Cluster & Silhouette \\
\hline Denmark & $\mathrm{C} 1$ & 0.680859 \\
\hline Finland & $\mathrm{C} 1$ & 0.641994 \\
\hline Norway & $\mathrm{C} 1$ & 0.5435 \\
\hline Sweden & $\mathrm{C} 1$ & 0.676786 \\
\hline Switzerland & $\mathrm{C} 1$ & 0.66847 \\
\hline United Kingdom & $\mathrm{C} 1$ & 0.611252 \\
\hline Bosnia and Her... & $\mathrm{C} 2$ & 0.67482 \\
\hline Bulgaria & $\mathrm{C} 2$ & 0.704253 \\
\hline Croatia & $\mathrm{C} 2$ & 0.701198 \\
\hline Czechia & $\mathrm{C} 2$ & 0.574372 \\
\hline Greece & $\mathrm{C} 2$ & 0.661046 \\
\hline Hungary & $\mathrm{C} 2$ & 0.701024 \\
\hline Italy & $\mathrm{C} 2$ & 0.695825 \\
\hline Latvia & $\mathrm{C} 2$ & 0.645645 \\
\hline Malta & $\mathrm{C} 2$ & 0.691334 \\
\hline Montenegro & $\mathrm{C} 2$ & 0.697911 \\
\hline North Macedonia & $\mathrm{C} 2$ & 0.6981 \\
\hline Poland & $\mathrm{C} 2$ & 0.66519 \\
\hline Portugal & $\mathrm{C} 2$ & 0.524934 \\
\hline Romania & $\mathrm{C} 2$ & 0.690453 \\
\hline Serbia & $\mathrm{C} 2$ & 0.699493 \\
\hline Slovakia & $\mathrm{C} 2$ & 0.653634 \\
\hline Turkey & $\mathrm{C} 2$ & 0.692918 \\
\hline Ukraine & $\mathrm{C} 2$ & 0.702027 \\
\hline Austria & $\mathrm{C} 3$ & 0.693186 \\
\hline Belgium & $\mathrm{C} 3$ & 0.686006 \\
\hline Cyprus & $\mathrm{C} 3$ & 0.635919 \\
\hline Estonia & $\mathrm{C} 3$ & 0.682315 \\
\hline France & $\mathrm{C} 3$ & 0.503773 \\
\hline Germany & $\mathrm{C} 3$ & 0.569479 \\
\hline Iceland & $\mathrm{C} 3$ & 0.630075 \\
\hline Ireland & $\mathrm{C} 3$ & 0.617829 \\
\hline Israel & $\mathrm{C} 3$ & 0.668625 \\
\hline Lithuania & $\mathrm{C} 3$ & 0.664668 \\
\hline Luxembourg & C3 & 0.636474 \\
\hline Netherlands & $\mathrm{C} 3$ & 0.669102 \\
\hline Slovenia & $\mathrm{C} 3$ & 0.602516 \\
\hline Spain & $\mathrm{C} 3$ & 0.67821 \\
\hline
\end{tabular}



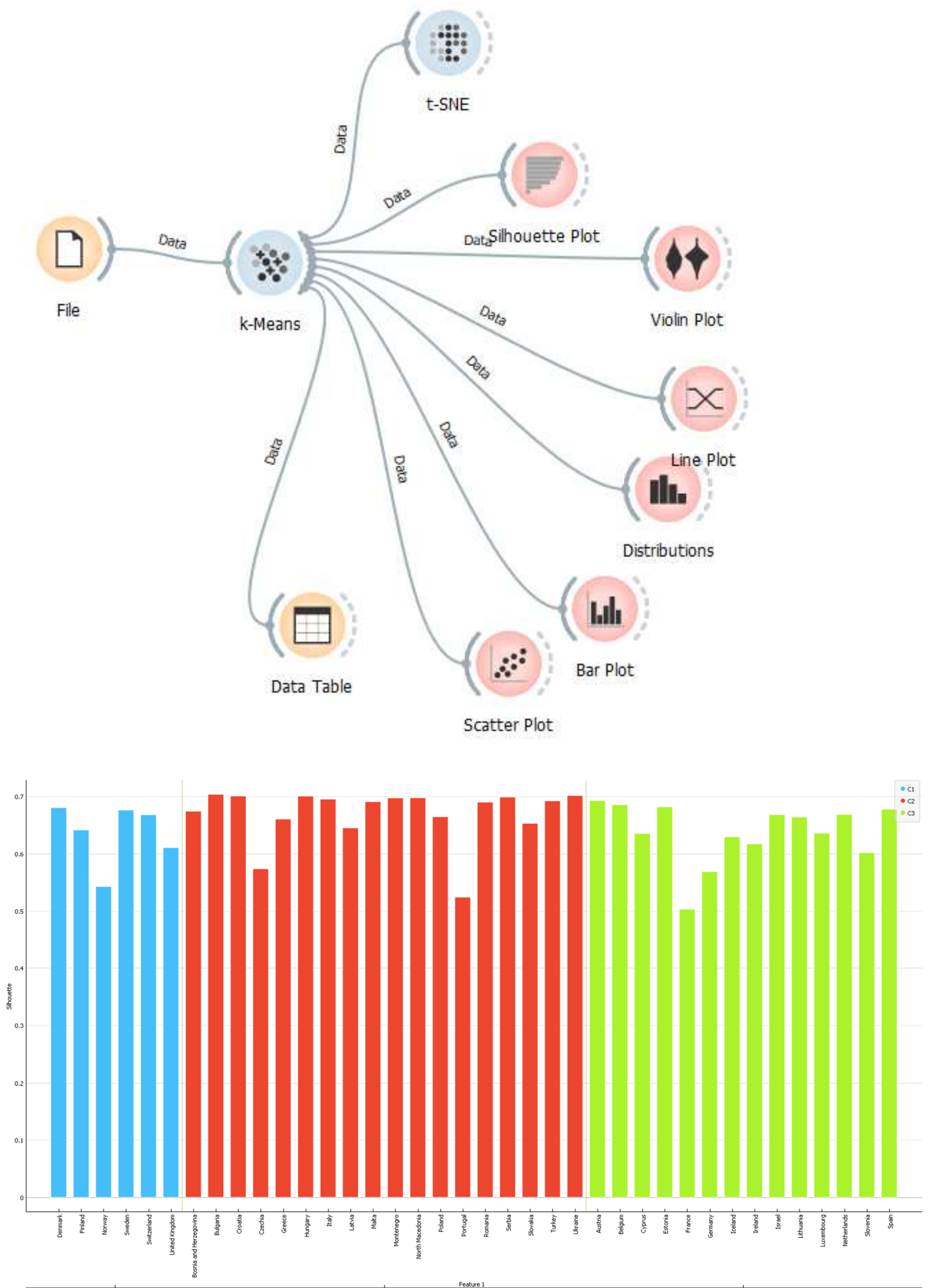


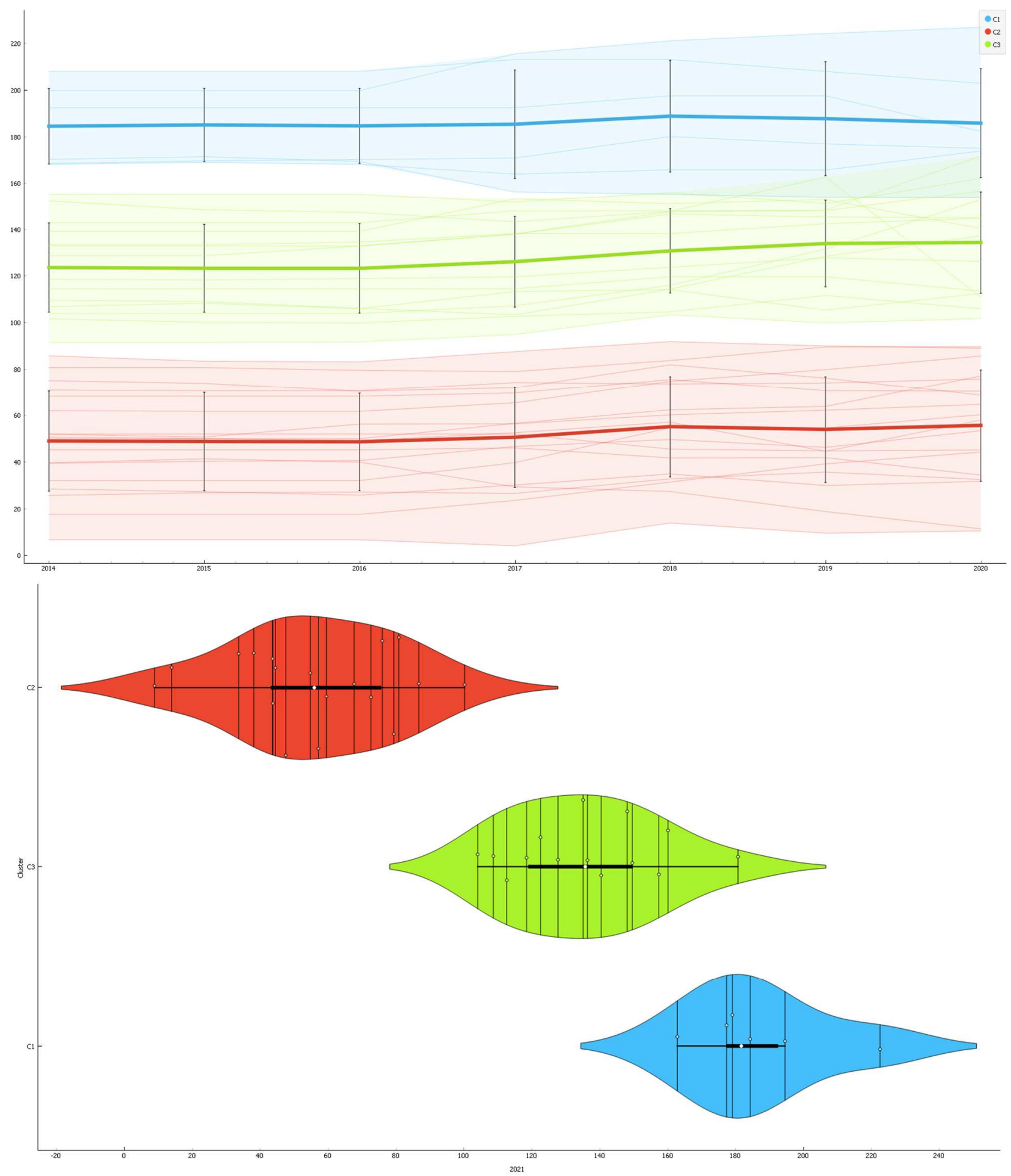



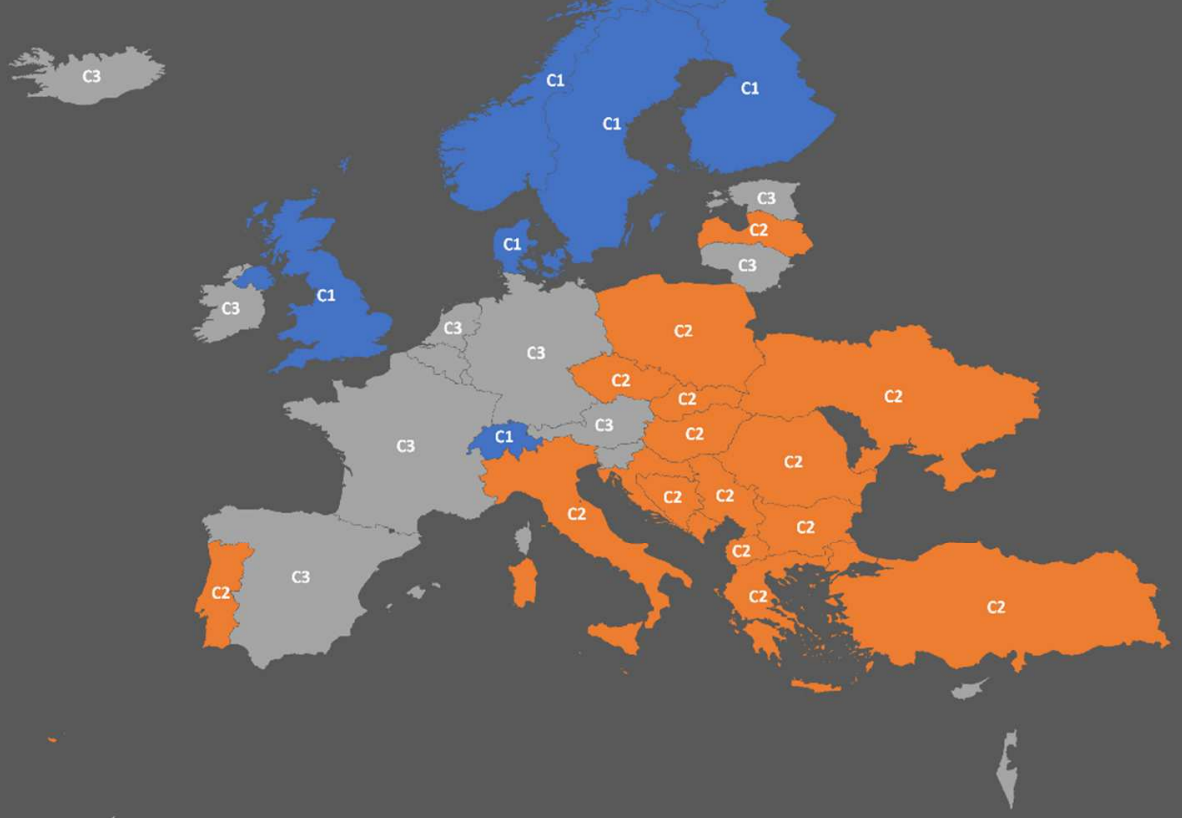

(1)
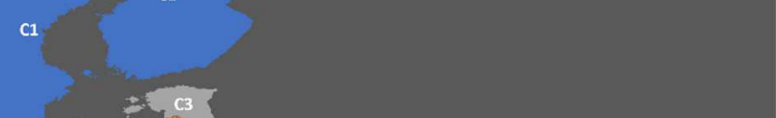

\subsection{Machine Learning and Prediction with KNIME}
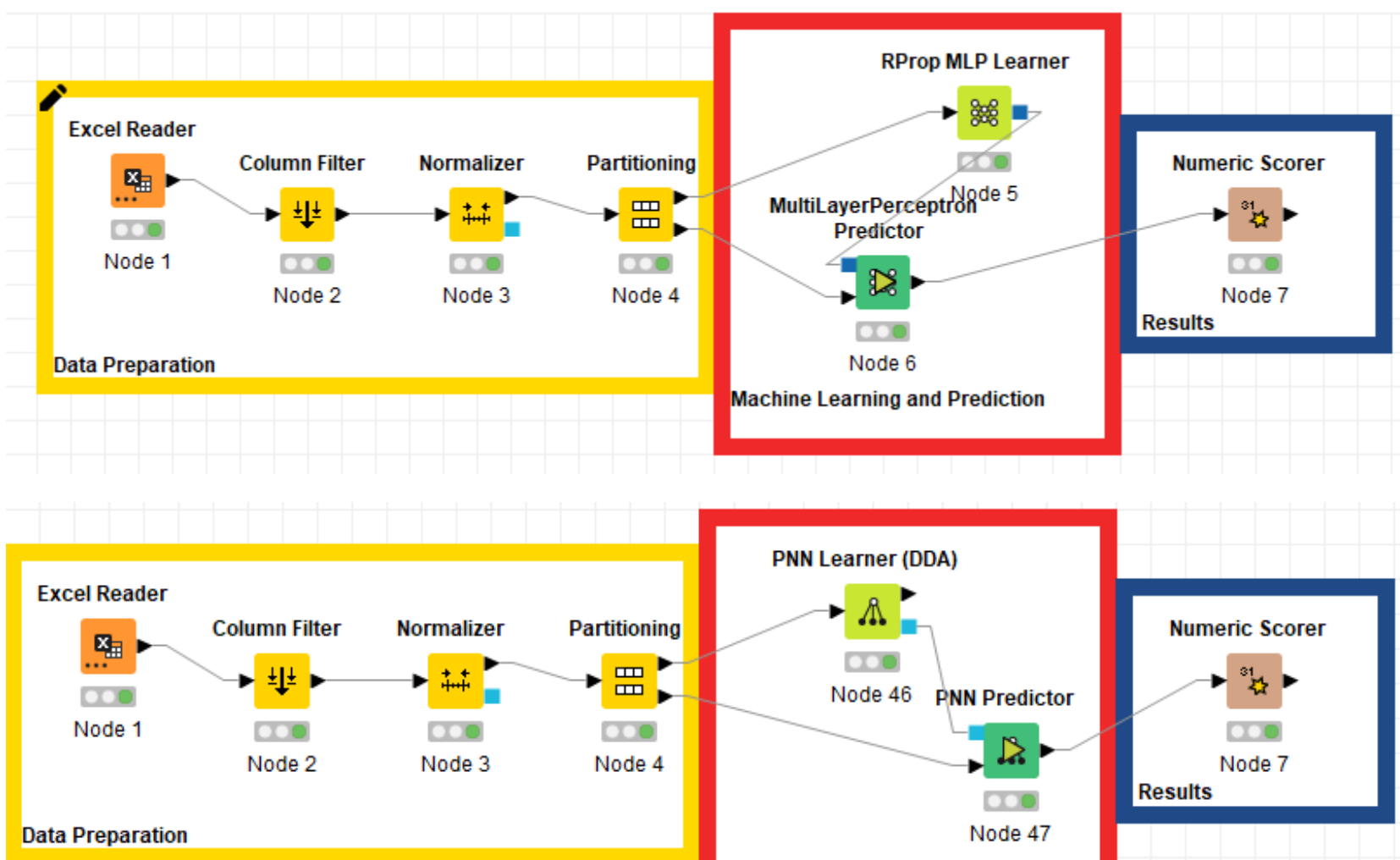

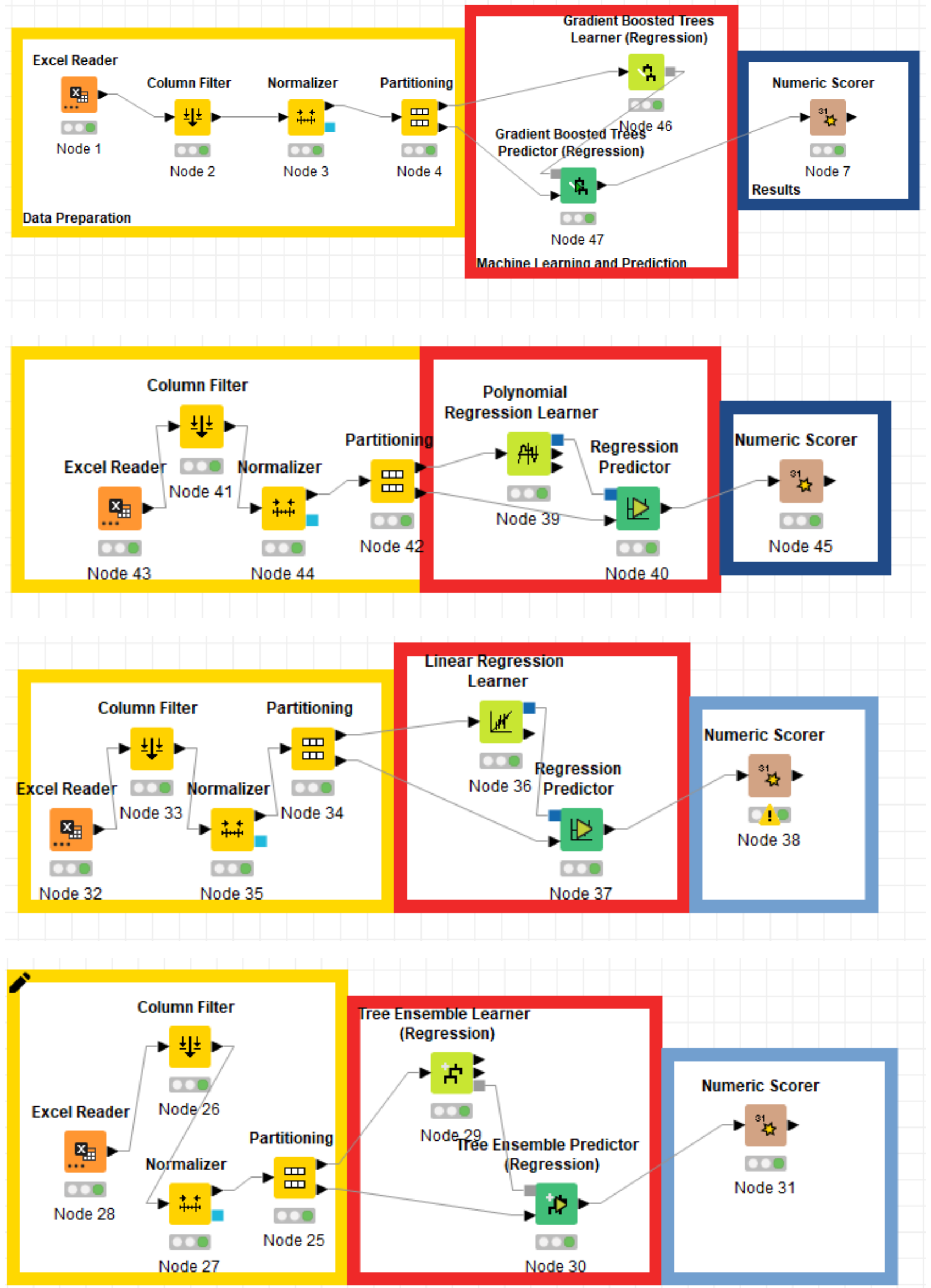
Random Forest Learner

(Regression)

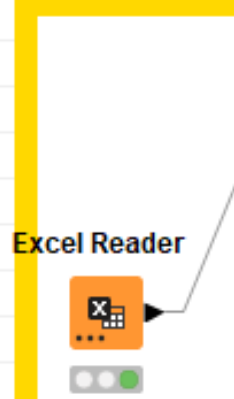

Node 21
Column Filter Normalizer

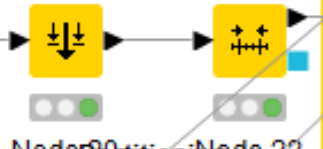

Nodereqrtitionihlgde 22

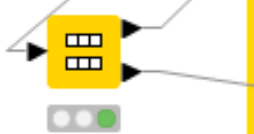

Node 23

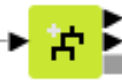

000

Node 18

Random Forest Predictor

(Regression)

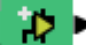

000

Node 19
Numeric Scorer

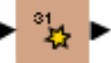

000

Node 24 


\begin{tabular}{|c|l|l|l|}
\hline \multicolumn{2}{|c|}{ Variables } & Label & Relations \\
\hline $\boldsymbol{y}$ & Human Resources & $A 23$ & \\
\hline $\boldsymbol{x}_{\mathbf{1}}$ & Basic-school entrepreneurial education and training & $A 4$ & + \\
\hline $\boldsymbol{x}_{\mathbf{2}}$ & Employment MHT manufacturing KIS services & $A 11$ & + \\
\hline $\boldsymbol{x}_{\mathbf{3}}$ & Employment share Manufacturing & $A 12$ & + \\
\hline $\boldsymbol{x}_{\mathbf{4}}$ & Government procurement of advanced technology products & $A 22$ & - \\
\hline $\boldsymbol{x}_{\mathbf{5}}$ & Lifelong learning & $A 32$ & + \\
\hline $\boldsymbol{x}_{\mathbf{6}}$ & Medium and high-tech product exports & $A 35$ & - \\
\hline $\boldsymbol{x}_{\mathbf{7}}$ & New doctorate graduates & $A 37$ & + \\
\hline $\boldsymbol{x}_{\mathbf{8}}$ & R\&D expenditure business sector & $A 46$ & + \\
\hline $\boldsymbol{x}_{\mathbf{9}}$ & R\&D expenditure public sector & $A 47$ & + \\
\hline $\boldsymbol{x}_{\mathbf{1}}$ & SMEs innovating in-house & $A 52$ & - \\
\hline $\boldsymbol{x}_{\mathbf{1 1}}$ & Tertiary education & $A 53$ & + \\
\hline $\boldsymbol{x}_{\mathbf{1}}$ & Venture capital & $A 59$ & - \\
\hline
\end{tabular}

\section{Figure 1}

Variables, Labels, and main relationships of the panel data econometric model estimated.

\begin{tabular}{|c|c|c|c|c|c|c|c|c|c|c|c|c|c|c|c|}
\hline \multirow[b]{3}{*}{ const } & \multicolumn{3}{|c|}{ DYNAMIC PANEL } & \multicolumn{3}{|c|}{ POOLED OLS } & \multicolumn{3}{|c|}{ FIXED EFFECTS } & \multicolumn{3}{|c|}{ RANDOM EFFECTS } & \multicolumn{3}{|c|}{ WLS } \\
\hline & \multirow{2}{*}{\begin{tabular}{r|} 
Coefficient \\
0,0362006
\end{tabular}} & \multicolumn{2}{|c|}{ P-value } & \multirow{2}{*}{\begin{tabular}{|r|r|} 
Coefficient \\
1,66348 \\
\end{tabular}} & \multicolumn{2}{|c|}{ P-value } & \multirow{2}{*}{\begin{tabular}{|c|} 
Coefficient \\
0,174644 \\
\end{tabular}} & \multicolumn{2}{|c|}{ P-value } & \multirow{2}{*}{\begin{tabular}{|c|} 
Coefficient \\
0,258045
\end{tabular}} & \multicolumn{2}{|c|}{ P-value } & \multirow{2}{*}{\begin{tabular}{|r|} 
Coefficient \\
0,164731 \\
\end{tabular}} & \multicolumn{2}{|c|}{ P-value } \\
\hline & & 0,9289 & & & 0,0302 & ** & & 0,7588 & & & 0,8219 & & & 0,6702 & \\
\hline$A 4$ & 0,212464 & $<0,0001$ & **** & 0,151388 & $<0,0001$ & **** & 0,131767 & $<0,0001$ & *** & 0,136655 & $<0,0001$ & w羊市 & 0,18446 & $<0,0001$ & 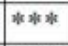 \\
\hline$A 11$ & & & $* * *$ & & & $* * *$ & & $<0,0001$ & $* * *$ & 0,215103 & $<0,0001$ & $* * *$ & 0,151996 & $<0,0001$ & **** \\
\hline$A 12$ & 0,140276 & 0,0027 & *** & 0,260197 & $<0,0001$ & $* * *$ & 0,142652 & $<0,0001$ & $* * *$ & 0,1595 & $<0,0001$ & **** & 0,157114 & $<0,0001$ & **** \\
\hline$A 22$ & -0.412619 & $<0,0001$ & $* * *$ & & $<0,0001$ & $* * *$ & $-0,464164$ & $<0,0001$ & $* * *$ & -0.470201 & $<0,0001$ & $* * *$ & $- 0 . 4 \longdiv { 0 2 8 8 }$ & $<0,0001$ & **** \\
\hline$A 32$ & 0,196726 & $<0,0001$ & **** & 0,20 & $<0,0001$ & $* * *$ & 214497 & $<0,0001$ & *** & 0,211251 & $<0,0001$ & 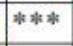 & 0,232997 & $<0,0001$ & *水水 \\
\hline A35 & $-0,0665088$ & 0,0036 & **** & $-8,0960481$ & $<0,0001$ & $* * *$ & $-0,0753852$ & $<0,0001$ & $* * *$ & $-0,07 \$ 062$ & $<0,0001$ & $* * *$ & $-0,06 \leqslant 1772$ & $<0,0001$ & **** \\
\hline$A 37$ & & & $* * *$ & & & & & & **: & 0,300994 & 001 & **** & 0,30548 & $<0$, & \\
\hline$A 46$ & 118728 & $<0,0001$ & $* * *$ & 0,10 & $<0,0001$ & $* * *$ & 04869 & $<0,0001$ & $* * *$ & 00508 & $<0,0001$ & **** & 0,0621947 & $<0,0001$ & **** \\
\hline$A 47$ & 0,096362 & 0,0201 & $* *$ & 0,168065 & $<0,0001$ & *** & 0,116663 & $<0,0001$ & *** & 0,129266 & $<0,0001$ & *** & 0,119997 & $<0,0001$ & **** \\
\hline A52 & $-0,062924$ & 0,0045 & **** & 0,133505 & $<0,0001$ & $* * *$ & $-0,072698$ & $<0,0001$ & $* * *$ & $-0,08215$ & $<0,0001$ & **** & $-0,082811$ & $<0,0001$ & 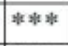 \\
\hline A53 & 0,292701 & $<0,0001$ & $* * *$ & 0,276928 & $<0,0001$ & *** & 0,26558 & $<0,0001$ & $* * *$ & 0,267027 & $<0,0001$ & $* * *$ & 0,299345 & $<0,0001$ & **** \\
\hline A59 & $-0,01 \$ 9627$ & 0,0827 & $*$ & $-\phi, 0308628$ & 0,0002 & **** & $-0,013922$ & 0,0625 & $*$ & $-0,016 \quad 321$ & 0,0275 & $* *$ & $-0,0127805$ & 0,0028 & \#水 \\
\hline$A 23(-1)$ & $-0,0094124$ & 0,4655 & & & & & & & & & & & & & \\
\hline
\end{tabular}

\section{Figure 2}

Synthesis of the main results of the panel data regressions. Source of data: European Innovation Scoreboard. 


\begin{tabular}{|c|c|c|c|}
\hline \multicolumn{4}{|c|}{$\begin{array}{l}\text { Ranking of the variables based on the mean value of the coefficient computed with } \\
\text { the } 5 \text { panel data techniques proposed in the model. }\end{array}$} \\
\hline Rank & Variables & Mean & Impact \\
\hline 1 & New doctorate graduates & 0,3014 & \multirow{8}{*}{ Positive } \\
\hline 2 & Tertiary education & 0,2803 & \\
\hline 3 & Lifelong learning & 0,2124 & \\
\hline 4 & Employment MHT manufacturing KIS services & 0,1977 & \\
\hline 5 & Employment share Manufacturing & 0,1719 & \\
\hline 6 & Basic-school entrepreneurial education and training & 0,1633 & \\
\hline 7 & $R \& D$ expenditure public sector & 0,1261 & \\
\hline 8 & $R \& D$ expenditure business sector & 0,0925 & \\
\hline 9 & Venture capital & $-0,0179$ & \multirow{4}{*}{ Negative } \\
\hline 10 & Medium and high-tech product exports & $-0,0765$ & \\
\hline 11 & SMEs innovating in-house & $-0,0876$ & \\
\hline 12 & Government procurement of advanced technology $\mathrm{pr}$ & $-0,4584$ & \\
\hline
\end{tabular}

Figure 3

Ranking of the variables based on the mean value of the coefficient computed with the 5 panel data techniques proposed in the model. Source: European Innovation Scoreboard.

\begin{tabular}{|c|c|c|c|c|}
\hline \multicolumn{5}{|c|}{$\begin{array}{c}\text { Characteristics of the Clusters for Level of Human Resources in } \\
2021 \text { in European Countries. Source: European Innovation } \\
\text { Scoreboard. }\end{array}$} \\
\hline Rank & Clusters & Mean Value & Min & Max \\
\hline 1 & Cluster 1 & 187,00 & 163,00 & 222,61 \\
\hline 3 & Cluster 2 & 56,00 & 8,95 & 100,26 \\
\hline 2 & Cluster 3 & 136,00 & 104,11 & 180,77 \\
\hline
\end{tabular}

Figure 4

Characteristics of the Clusters for the level of Human Resources in 2021 in European Countries. Source: European Innovation Scoreboard. 


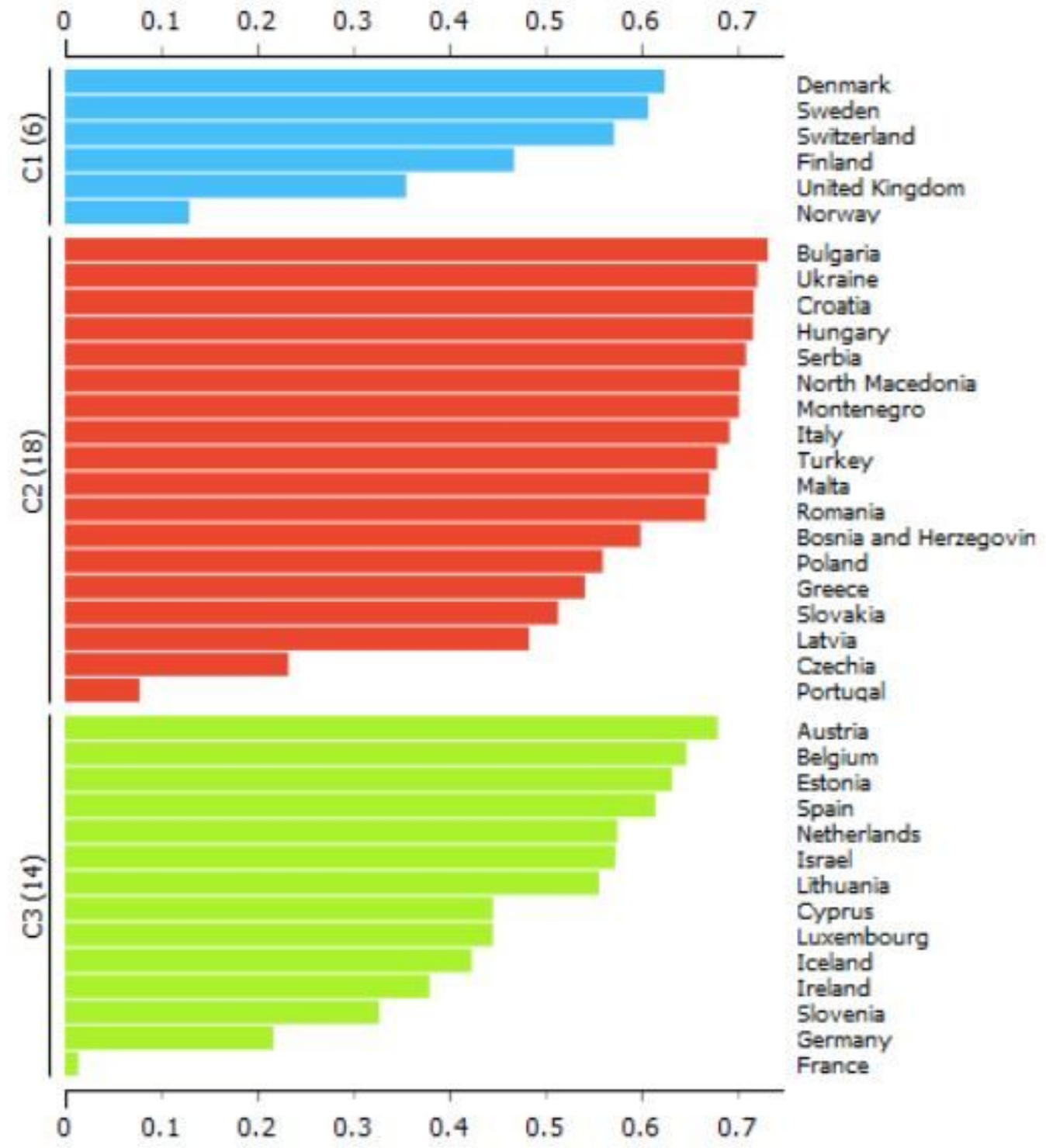

Figure 5

Clusterization of European Countries in 2021 based on the level of Human Resources. Source: European Innovation Scoreboard. Tool: Orange. Algorithm: k-Means. Optimization: Silhouette Coefficient. 


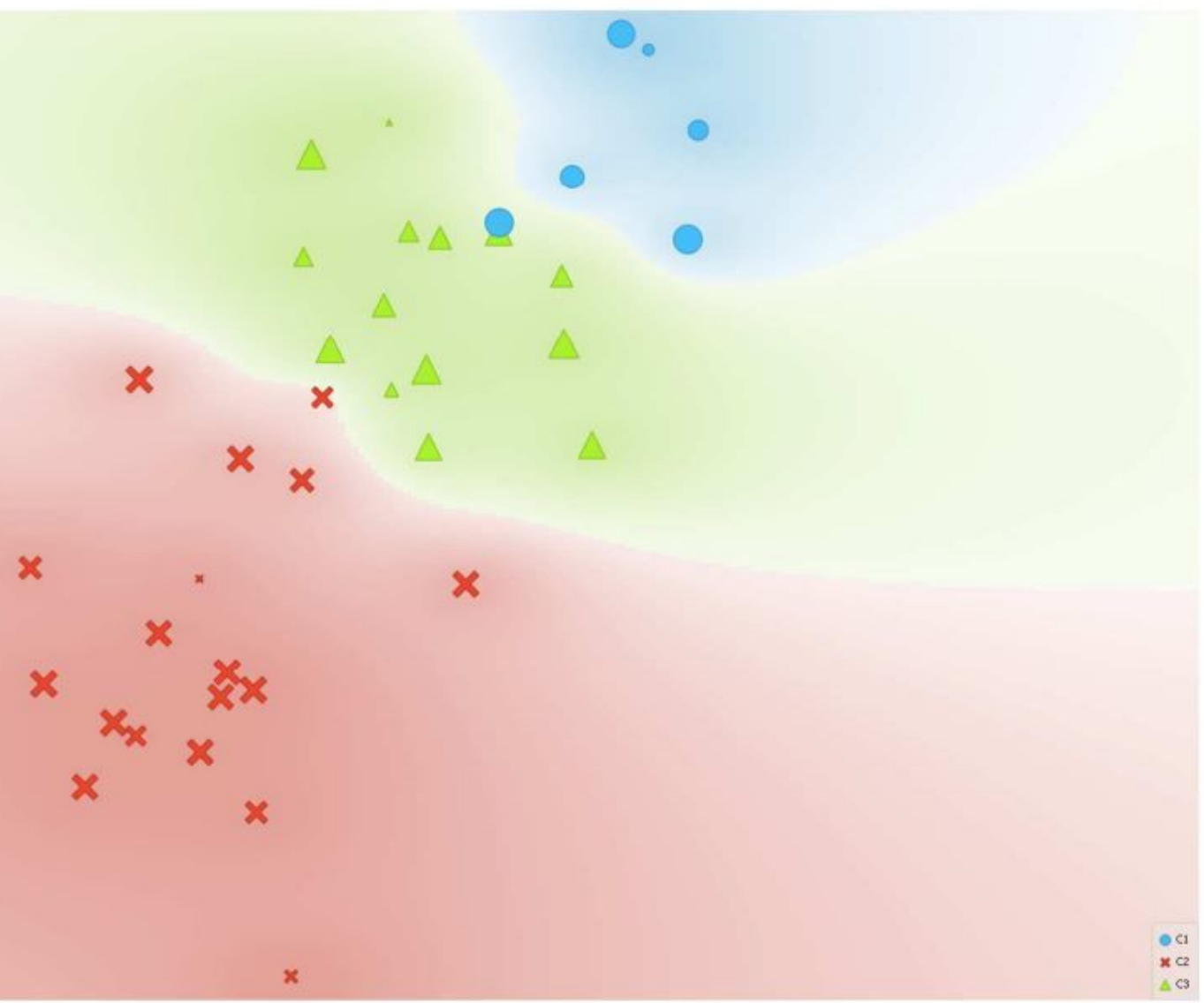

Figure 6

Representation of the clusterization with the algorithm t-SNE. Tool: Orange. Source: European Innovation Scoreboard. Year: 2021.

\begin{tabular}{l|l|r|r|r|r|r|}
\hline \multicolumn{7}{|c|}{ Machine Learning and Prediction of Human Resources in Europe. Source: European Innovation Scoreboard. } \\
\hline & $\boldsymbol{R}^{\wedge} \mathbf{2}$ & Mean Absolute Error & Mean Squared Error & Root Mean Squared Error & Mean Signed Difference \\
\hline ANN & 0,9626 & 0,0370 & 0,0030 & 0,0552 & 0,0679 \\
\hline PNN & 0,8853 & 0,0622 & 0,0046 & 0,0226 \\
\hline GRADIENT BOOSTED TREES & 0,9036 & 0,0492 & 0,0039 & 0,0114 \\
\hline RANDOM FOREST REGRESSION & 0,9380 & 0,0532 & 0,0039 & 0,0623 & 0,0625 \\
\hline TREE ENSEMBLE REGRESSION & 0,9569 & 0,0364 & 0,0018 & 0,0420 & 0,0093 \\
\hline LINEAR REGRESSION & 0,9787 & 0,0270 & 0,0011 & 0,0019 & 0,0331 & \\
\hline POLYNOMIAL REGRESSION & 0,9681 & 0,0396 & 0,0078 \\
\hline
\end{tabular}

\section{Figure 7}

Results of the Machine Learning and Prediction Algorithms using KNIME 


\section{Machine Learning and Prediction of Human Resources in Europe. Source: European Innovation Scoreboard.}

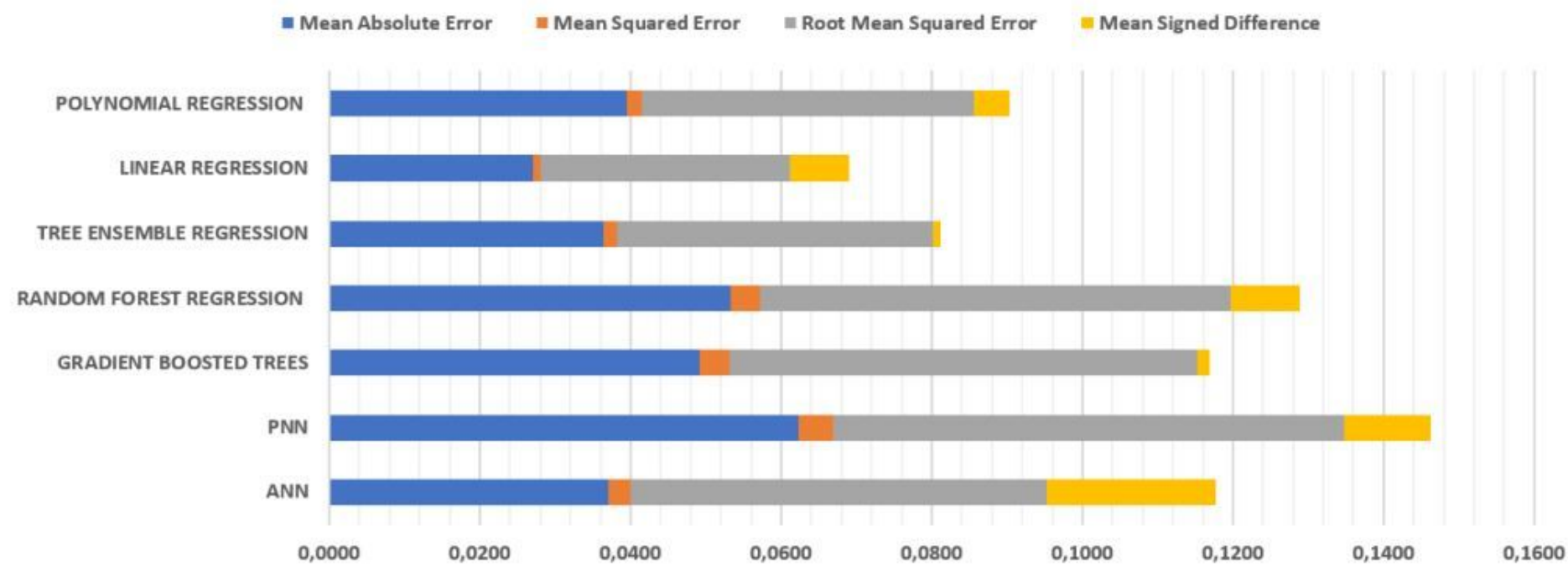

\section{Figure 8}

Results of Machine Learning and Prediction Algorithms using KNIME. Linear Regression, in the combination of learner and prediction, has the lower values of estimated errors.

\section{Supplementary Files}

This is a list of supplementary files associated with this preprint. Click to download.

- AngeloLeograndePRediction1.png

- 11092021Clusterization2.png

- 11092021Clusterization3.png

- 11092021Clusterization4.png

- 11092021Clusterization5.png

- 11092021Clusterization.png

- 11092021clusters6.png

- 11092021Clusters.png

- 11092021ScatterPlot.png 